\title{
MicroRNA profiling of the pubertal mouse mammary gland identifies miR-184 as a candidate breast tumour suppressor gene
}

Yu Wei Phua 1,2, Akira Nguyen ${ }^{1,2}$, Daniel L. Roden 1,2, Benjamin Elsworth ${ }^{1,2}$, Niantao Deng ${ }^{1,2}$, Iva Nikolic ${ }^{1,2}$, Jessica Yang ${ }^{1}$, Andrea Mcfarland ${ }^{1}$, Roslin Russell ${ }^{3}$, Warren Kaplan ${ }^{1}$, Mark J. Cowley ${ }^{1,2}$, Radhika Nair ${ }^{1,2}$, Elena Zotenko ${ }^{1,2}$, Sandra O'Toole ${ }^{1,2,4,5}$, Shi-xiong Tan ${ }^{6}$, David E. James ${ }^{5,7}$, Susan J. Clark ${ }^{1,2}$, Hosein Kouros-Mehr ${ }^{8}$ and Alexander Swarbrick ${ }^{1,2^{*}}$

\begin{abstract}
Introduction: The study of mammalian development has offered many insights into the molecular aetiology of cancer. We previously used analysis of mammary morphogenesis to discover a critical role for GATA-3 in mammary developmental and carcinogenesis. In recent years an important role for microRNAs (miRNAs) in a myriad of cellular processes in development and in oncogenesis has emerged.

Methods: microRNA profiling was conducted on stromal and epithelial cellular subsets microdissected from the pubertal mouse mammary gland. miR-184 was reactivated by transient or stable overexpression in breast cancer cell lines and examined using a series of in vitro (proliferation, tumour-sphere and protein synthesis) assays. Orthotopic xenografts of breast cancer cells were used to assess the effect of miR-184 on tumourigenesis as well as distant metastasis. Interactions between miR-184 and its putative targets were assessed by quantitative PCR, microarray, bioinformatics and 3' untranslated region Luciferase reporter assay. The methylation status of primary patient samples was determined by MBD-Cap sequencing. Lastly, the clinical prognostic significance of miR-184 putative targets was assessed using publicly available datasets.

Results: A large number of microRNA were restricted in their expression to specific tissue subsets. MicroRNA-184 (miR-184) was exclusively expressed in epithelial cells and markedly upregulated during differentiation of the proliferative, invasive cells of the pubertal terminal end bud (TEB) into ductal epithelial cells in vivo. miR-184 expression was silenced in mouse tumour models compared to non-transformed epithelium and in a majority of breast cancer cell line models. Ectopic reactivation of miR-184 inhibited the proliferation and self-renewal of triple negative breast cancer (TNBC) cell lines in vitro and delayed primary tumour formation and reduced metastatic burden in vivo. Gene expression studies uncovered multi-factorial regulation of genes in the AKT/mTORC1 pathway by miR-184. In clinical breast cancer tissues, expression of miR-184 is lost in primary TNBCs while the miR-184 promoter is methylated in a subset of lymph node metastases from TNBC patients.
\end{abstract}

Conclusions: These studies elucidate a new layer of regulation in the PI3K/AKT/mTOR pathway with relevance to mammary development and tumour progression and identify miR-184 as a putative breast tumour suppressor.

\footnotetext{
* Correspondence: a.swarbrick@garvan.org.au

${ }^{1}$ The Kinghorn Cancer Centre \& Cancer Research Division, Garvan Institute of Medical Research, 370 Victoria Street, Darlinghurst, NSW, Sydney, Australia ${ }^{2}$ St Vincent's Clinical School, Faculty of Medicine, Sydney, UNSW, Australia Full list of author information is available at the end of the article
} 


\section{Introduction}

Breast cancer is the most common malignancy that occurs in women globally [1]. Despite the advancement in therapies, many women will suffer from relapse, acquiring metastatic lesions in distant sites and eventually succumbing to cancer related deaths [2-4]. Currently there is a lack of targeted therapies, in particular towards the triple negative breast cancer (TNBC) subtype. TNBC are aggressive and highly invasive, and these tumours lack estrogen receptor (ER), progesterone receptor (PR) and human epidermal growth factor 2 (HER2) expression [5].

A large body of evidence has identified augmented receptor tyrosine kinase (RTK)-PI3K-Akt-mTOR activity in the basal like and TBNCs either due to mutations in RTKs or PIK3CA or loss of phosphatase and tensin homologue (PTEN) expression [6-9]. This pathway has therefore become a major focus of breast cancer drug development, although patient responses to these novel drug compounds in clinical trials have been variable, perhaps due to an incomplete understanding of pathway interactions and feedback loops. Clearly, a thorough understanding of the regulation of these signalling pathways is essential to effectively personalise breast cancer treatment.

microRNAs (miRNAs) are small non coding RNAs that modulate gene expression post transcriptionally. They typically silence their targets by binding their 3' untranslated regions (UTRs) in a sequence-specific manner [10]. There are a wealth of experimental data demonstrating the pleiotropy of miRNAs in regulating a multitude of cellular processes, such as embryonic stem cell differentiation [11, 12], cell fate and lineage commitment [13-15], organogenesis [16-18] and oncogenesis [19-23].

The pubertal developing mammary gland is elaborated through fat pad invasion by terminal end buds (TEBs); poorly differentiated, unpolarised, proliferative and invasive structures [24] that are enriched for stem and progenitor cell activity [25], with many cellular and molecular similarities to neoplastic cells [26]. We previously examined the expression of mRNAs between cellular subsets of the developing mammary gland, found GATA-3 to be specifically expressed in epithelial cells and went on to identify GATA-3 as an important breast tumour suppressor gene $[27,28]$.

In this study, we comprehensively profiled miRNA expression in the different cellular compartments within the mammary epithelium of mice. We identify miR-184 as a microRNA associated with epithelial differentiation and demonstrated that miR-184 is silenced and methylated in a subset of TBNC. Further functional characterisation of miR-184 revealed that it is a potential tumour suppressor miRNA in breast cancer; in suppressing cell proliferation, self-renewal in vitro and delaying the formation of metastatic lesions in distant sites in vivo. By performing microarray studies and informatic analysis, we discovered that miR-184 regulates the AKT/mTORC1 pathway by targeting AKT2, TSC2 and PRAS40 in suppressing activity of S6K1 and protein synthesis.

\section{Methods}

\section{Expression profiling of TEBs, ducts and stroma}

TEBs $(\mathrm{n}=4)$, mature ducts $(\mathrm{n}=4)$, and distal stroma regions $(n=4)$ were microdissected from mammary glands of anaesthetised 5-week-old $\beta$-actin-GFP reporter mice (FVB/n, Jackson laboratory, Bar Habor, Maine, USA) using a Leica fluorescence microscope (Leica microsystems, Wetzlar, Germany). Tissue samples were homogenised in Trizol Reagent (Life Technologies, Carlsbad, CA, USA) with a polytron tissue homogeniser (Thermo Fisher Scientific, Waltham, MA, USA). Total RNA was extracted according to a modified protocol based on the manufacturer's instructions (Invitrogen). The final RNA pellet was ethanol precipitated and washed in $80 \%$ ethanol. RNA samples consisting of TEBs $(n=3)$, mature ducts $(n=2)$ and stroma $(n=3)$ were sent to the Ramaciotti Centre for Gene Function Analysis for miRNA microarray profiling (University of New South Wales, Sydney, Australia) using the SurePrint Mouse miRNA Array V2 (Agilent Technologies, Santa Clara, CA, USA). All animal work was approved by the Garvan/St Vincent's Hospital Animal Ethics Committee and conducted in accordance with NHMRC guidelines for the ethical treatment of animals.

\section{Cell lines, retroviral infections}

MDA-MB-231 and BT549 cells were maintained in RPMI 1640 supplemented with $10 \%$ FBS and $0.25 \%$ human insulin. HEK293E cells were maintained in DMEM supplemented with $10 \%$ FBS. MDA-MB-231 cells were obtained from the EG \& G Mason Research Institute, Worcester, Massachusetts, USA and DNA fingerprinted. BT-549 cell lines were obtained from ATCC. All cell lines used in experiments were cultured at $37{ }^{\circ} \mathrm{C}$ in $5 \% \mathrm{CO}_{2}$ and $95 \%$ air. MDA-MB-231 cells were first transduced with the retroviral vector $\mathrm{pRQ}-\mathrm{rtTA}-\mathrm{GFP}$ followed by pRQ-miR184.

\section{Primary tumour samples}

Human tumour samples consisting of luminal A $(E R+$, PR+, Her2-; $\mathrm{n}=10$ ), Her2 (ER-, PR-, Her2+; n = 9), triple negative (ER-, PR-, Her2-; $\mathrm{n}=7$ ) and matched normal $(n=7)$ were obtained from the Victoria Cancer Biobank (VCB). Research use of human tissues was approved by the St Vincents Hospital Human Research Ethics Committee (Approval \# 08/145). Tumour samples were homogenised using a mortar and pestle. Total RNA samples were extracted using miRVana kit (Invitrogen) and ethanol precipitated with $80 \%$ ethanol. 


\section{Transfection with miRNA mimics}

For MDA-MB-231 and BT549 cells, miRIDIAN miRNA mimics (Dharmacon, Lafayette, CO, USA) were transfected into cells using Lipofectamine 2000 (Invitrogen) according to the manufacturer's protocol for transfecting siRNA. Mimics (final concentration of $50 \mathrm{nM}$ ) were mixed with $1 \%$ lipofectamine 2000 (v/v) diluted in Opti-MEM transfection medium (Invitrogen) and incubated for 20 minutes. The mimics were added dropwise onto cells in growth medium at a final concentration of $50 \mathrm{nM}$. Fresh medium was replaced $24 \mathrm{~h}$ post transfection. A nonradioactive cell proliferation assay (Promega, Madison, WI, USA) was used to assess the number of viable cells. Three biological replicates were conducted.

MDA-MB-436 and HS578T breast cancer cells were reverse transfected with $40 \mathrm{nM}$ of either miR-184 mimic or scrambled using Dharmafect 4 reagent (Dharmacon) following manufacturer's instructions; SiTox (Dharmacon) was used as a positive control. The following day, medium was changed and cells were left in culture for an additional 72 h. To assess viability, CellTiter-Glo (Promega) was added directly into the cell medium (1:2 ratio) and left to incubate for 10 minutes; luminescence was read using FLUOstar Omega plate reader (BMG Labtech, Ortenburg, Germany). The experiment was performed in three biological replicates.

\section{Quantitative RT-PCR}

Total RNA was extracted using the Trizol reagent (Invitrogen) method with a modification where the final RNA pellet was ethanol precipitated and washed in $80 \%$ ethanol. cDNA was generated using the Taqman MiRNA Reverse Transcription Kit (Applied Biosystems) using the specific primer from TaqMan MiRNA assay (Applied Biosystems) according to the manufacturer's protocol. Quantitative PCR (qPCR) amplification was run on the 7900 Real-time PCR system (Applied Biosystems). All human and mouse miRNA expression values were normalised to RNU6B and SnoRNA202, respectively.

\section{Immunoblot and 3' UTR luciferase activity assay}

Cells were lysed using complete radioimmune precipitation assay (RIPA) buffer supplemented with complete ULTRA protease inhibitor cocktail tablets (Roche, Basel, Switzerland) and sodium orthovanadate. Anti-Akt2, anti-phospho-Akt (Thr308), anti-phospho-Akt (Ser473), anti-Pras40, antiphospho-Pras40 (Thr246), anti-Gsk3A, anti-phospho-Gsk3 (Ser21/9), anti-Tsc2, anti-phospho-Tsc2 (Thr1426), antimTOR, anti-phospho-mTOR (Ser2448), anti-p70S6k1, anti-phospho-p70S6k1 (Thr389), anti-p70S6K2, anti-4EBP1, anti-4E-BP1 (Thr37/46) (Cell Signalling Technology, Danver, Massachusetts, USA) rabbit polyclonal antibodies were used in immunoblotting. Luciferase constructs (pLight Switch_3'UTR) (Switchgear genomics, Carlsbad, CA, USA) containing the 3' UTR region of Akt2, Pras40, Gsk3a, CSF1 and Itgb1 was individually transfected into HEK293T cells using pGL4.12 (luc2CP) as a normaliser. Luciferase activity was measured by using the dual luciferase assay (Promega).

\section{Tumoursphere assays}

MDA-MB-231 cells were cultured in serum-free RPMI 1640, supplemented with B27 (Invitrogen) and $20 \mathrm{ng} / \mathrm{ml}$ bFGF (BD Biosciences, Franklin Lakes, NJ, USA), and 4 $\mu \mathrm{g} / \mathrm{ml}$ heparin (Sigma Aldrich, St. Louis, MO, USA) and plated at 15,000 viable cells/well in ultralow attachment 6-well plates (Corning Incorporate, NY, USA). Complete serum-free medium was added to the cells every 3 days. Primary tumourspheres were enumerated at day 10. Primary tumourspheres were collected, and were enzymatically dissociated into single cells, re-plated in ultralow attachment 6-well plates (Corning Incorporate) at a density of 1,000 viable cells/well and enumerated at day 10 .

\section{Protein synthesis assay}

Cells were washed twice and serum starved for 16-18 h prior to EGF stimulation. Cells were stimulated with EGF in serum-free DMEM low glucose without L-ARG, L-LEU, L-LYS, sodium pyruvate and phenol red (Sigma Aldrich) for $1 \mathrm{~h}$ : $\left[{ }^{3} \mathrm{H}\right]$ Leucine (PerkinElmer, Waltham, MA, USA) was added at the same time as EGF to a final concentration of $5 \mu \mathrm{Ci} / \mathrm{ml}$. Cells were washed three times in ice-cold PBS, lysed using RIPA buffer followed by incubating cells with $10 \%$ trichloroacetic acid (TCA) for 10 minutes to precipitate proteins. Pellets were washed three times in $10 \%$ TCA. Pellets were resuspended in $50 \mathrm{nM}$ $\mathrm{NaOH}$ with $1 \%$ Triton $\mathrm{X}-100$ at $65{ }^{\circ} \mathrm{C}$ for 30 minutes or until the pellet dissolved. The radioactivity of samples was assessed by measuring the scintillation count using the $\beta$-scintillation counter. The results were normalised for protein content using bicinchoninic acid (BCA) analysis.

\section{Animal experiments}

For primary tumour burden and spontaneous metastasis assays, $1 \times 10^{6}$ MDA-MB-231 cells were injected into the mammary fat pad of 8-week-old female NOD/SCID mice. Mice were culled at the ethical end point, and primary tumour and other organs such as lungs, spleen, lymph node, pancreas and brain were harvested. Metastatic lesions were quantified with a fluorescent microscope within $2 \mathrm{~h}$ of harvest.

\section{Immunohistochemistry}

Mouse tissues were extracted and fixed overnight at $4{ }^{\circ} \mathrm{C}$ in $10 \%$ neutral-buffered formalin (Sigma), and stored in $70 \%$ ethanol at $4{ }^{\circ} \mathrm{C}$. Subsequently, tissues were embedded in paraffin and sectioned. Sections were stained with haematoxylin and eosin (H\&E) and phospho-histone H3 (Cell signaling) in accordance with standard protocols. Scoring of phospho-Histone $\mathrm{H} 3$ immunostaining and mitotic figures was assessed by a specialist breast pathologist (SO'T). 


\section{Gene expression analysis}

MDA-MB-231 cells were transfected with miR-184 or control mimics for $48 \mathrm{~h}$ before total RNA was extracted using the modified Trizol reagent protocol with an additional ethanol precipitation step. RNA samples were sent off to the Ramaciotti Centre for Gene Function Analysis for gene expression profiling using the affymetrix gene 1.0ST array (Affymetrix) (University of New South Wales, Sydney, Australia). Gene expression analysis was performed using gene pattern.

\section{Statistical analysis}

Statistical analysis was performed by using GraphPad Prism v6.0. $\mathrm{T}$ tests were performed to determine statistical significance, unless otherwise stated. $P<0.05$ was considered statistically significant.

\section{Methylation analysis}

The MBDCap-Seq experiment was performed by Dr Claire Stirzaker and Dr Jenny Song (Garvan Institute of Medical Research). Analysis of the results was performed by Dr Elena Zotenko (Garvan Institute of Medical Research). Briefly, methylated DNA was isolated using the MethylMinerTM Methylated DNA Enrichment Kit (Life Technologies). Genomic FFPET DNA was sonicated. MBD-Biotin Protein $(3.5 \mu \mathrm{g})$ was coupled to $10 \mu \mathrm{l}$ of Dynabeads M-280 Streptavidin according to the manufacturer's instructions.

MBD biotin conjugated to the magnetic beads was washed three times and resuspended in one volume of $1 \times$ bind/wash buffer. The capture reaction was performed by adding $500 \mathrm{ng}$ to $1 \mu \mathrm{g}$ sonicated DNA to the MBD-magnetic conjugates on a rotating mixer for $1 \mathrm{~h}$ at room temperature (RT). All capture reactions were done in duplicate. The beads were washed three times with $1 \times$ bind/wash buffer. The bound methylated DNA was eluted using single high-salt elution buffer (2 M $\mathrm{NaCl})$. Eluted DNA fraction was concentrated by ethanol precipitation using $1 \mu \mathrm{l}$ glycogen $(20 \mu \mathrm{g} / \mu \mathrm{l}), 1 / 10$ volume of $3 \mathrm{M}$ sodium acetate, $\mathrm{pH} 5.2$ and two sample volumes of $100 \%$ ethanol, and resuspended in $60 \mu \mathrm{l}$ water.

\section{Preparation of MBDCap-Seq libraries and Illumina sequencing}

DNA, $10 \mathrm{ng}$, was prepared for Ilumina sequencing using the Illumina ChIP-Seq DNA sample prep kit (Illumina, San Diego, CA, USA) according to the manufacturer's instructions. The library preparation was analysed on Agilent High Sensitivity DNA 1000 Chip. Each sample was sequenced on one lane of the GA11x.

\section{Alignment of MBDCap-Seq data}

Sequenced reads were aligned to the hg18 version of the human genome with bowtie [29]. Sequence reads with three mismatches or more and reads mapping to multiple positions were excluded. Last, multiple reads mapping to exactly the same genomic coordinate were eliminated and only one read was retained for downstream analysis.

\section{miRNA seed match analysis}

The seed match analysis was performed as previously described by Melton et al. [30]. Briefly, ensemble transcripts (hg19) of promoter, 5' UTR, open reading frame (ORF) and 3' UTRs and other annotated genes (hg19) were obtained from the UCSC Genome Browser. Relevant miRNA seed match (7mer-1A or 7 mer-m8) was conducted on those transcripts using a custom Python script [30]. Results from seed match analysis were mapped to Affymetrix IDs. Wilcoxon rank sum test was used to determine the $p$ values in this analysis.

\section{Gene signature score and survival analysis}

A stringent 18-gene signature repressed by miR-184 (fold-change $>2$, Table 2) was assessed for survival analysis using two independent cohorts from METABRIC [31] and a cohort of women receiving neo-adjuvant chemotherapy [32]. METABRIC gene expression data were downloaded from the European Genome-Phenome Archive (EGAS00000000083). Gene expression and clinical data from Hatzis et al. were downloaded from Gene Expression Omnibus (GEO) [GEO: GSE25066]. The gene signature score was defined by a weighted average method [33] for each sample in the METABRIC discovery cohort. Survival curves were estimated using the Kaplan-Meier method, with overall survival used as the outcome metric.

\section{Results}

Identification of microRNAs enriched in mammary cellular compartments

We performed miRNA expression profiling on microdissected stroma, mature ducts and TEBs of pubertal 5-week-old GFP+ mice to identify miRNAs involved in mammary gland development (Fig. 1a). Each cellular fraction expressed a set of unique microRNAs (Fig. 1b). We identified a set of miRNAs that were specific to the stroma, ducts, TEBs or both epithelial fractions (Fig. 1b; Table 1). miR-31 was the most highly enriched miRNA expressed in the TEBs, approximately 10.7-fold upregulated versus ducts. When we performed unsupervised hierarchical clustering (Fig. 1b), and miR-31 was tightly clustered to several members of the proto-oncogenic miR 17-92 cluster, such as miR-17, miR-18a and miR-19a. Conversely, miR-184 expression was significantly enriched approximately 4.2 -fold in the mature ducts compared to the TEBs. Interestingly, miR-184, being the most highly enriched miRNA in the mature ducts was clustered tightly 


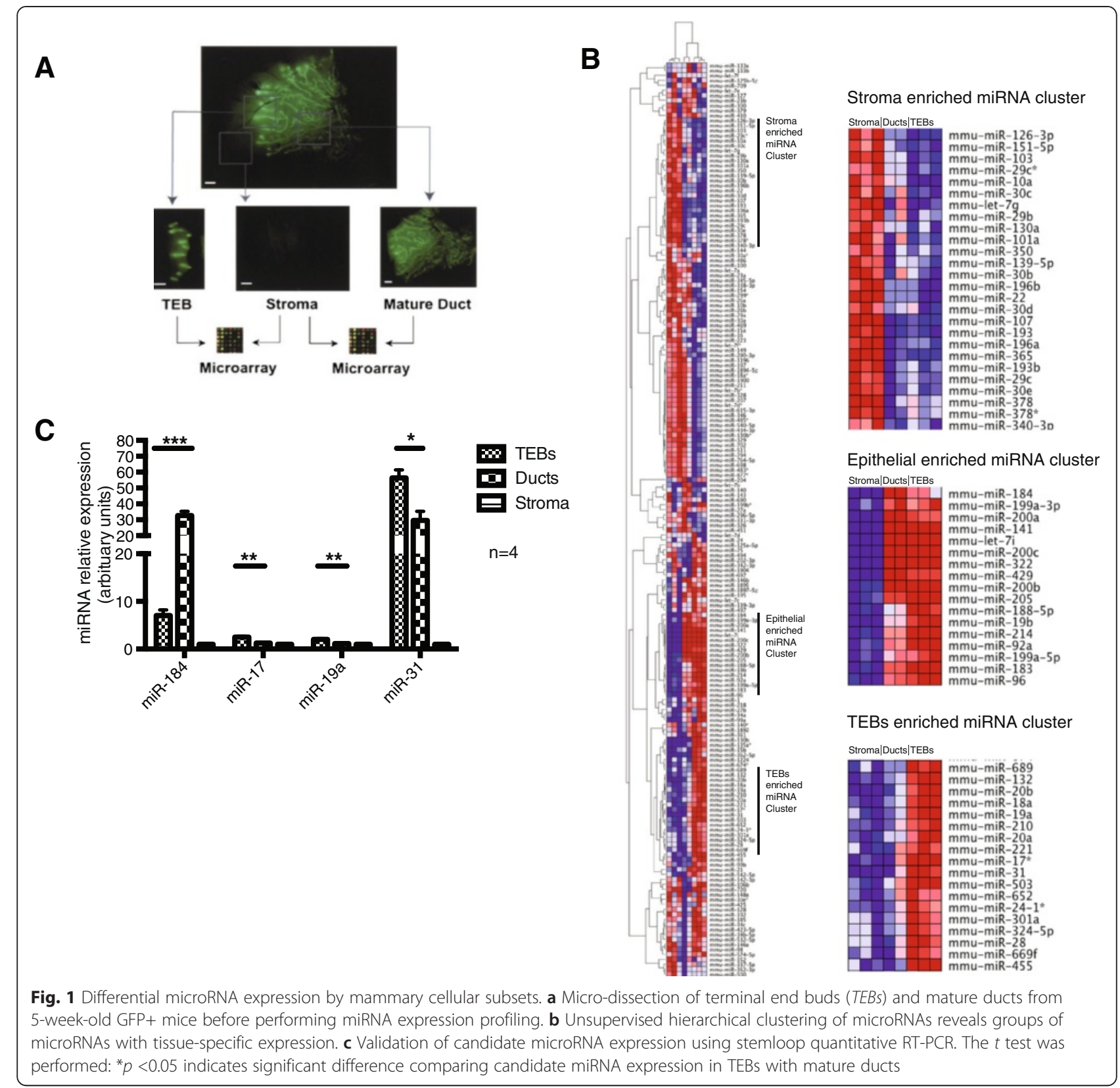

to a subset of epithelial specific miRNAs, which included members of the miR-183 family (miR-183, miR-96) and all members of the miR-200 family (miR-141, miR-200a, miR-200b, miR-200c and miR-429). We validated the expression of miR-31, miR-184, miR-17 and miR-19a in TEBs and ducts by quantitative RT-PCR (Fig. 1c).

miR-184 expression is attenuated in mouse models of breast cancer and human breast cancer cell lines

To examine whether microRNAs differentially regulated through morphogenesis are also deregulated in cancer, we examined miRNA expression in four mouse tumour models compared to normal total mammary epithelium: spontaneous $T p 53^{-/-}$tumours [34], transgenic C3 SV40 tag model [35], transgenic MMTV-Neu [36] and transgenic MMTV-PyMT [37]. There are several advantages of using these tumour models: first, each tumour model has been well characterised and the initiating oncogene that drives tumourigenesis in these models is known. Second, each tumour model has its matched normal counterpart as a comparison. Last, these tumour models recapitulate different subtypes of human breast cancer.

miR-31 was highly expressed in all of the murine tumours when compared to the normal murine mammary epithelial cells (Additional file 1: Figure S1D). In contrast, the expression of miR-184 was almost abrogated in the 
Table 1 Candidate microRNAs enriched in the terminal end buds (TEBs) or mature ducts, ranked by fold change

\begin{tabular}{llllll}
\hline Rank & Upregulated & microRNA candidate & microRNA family & $Q$ value & Fold change (TEB/duct) \\
\hline 1 & TEB & mmu-miR-31 & miR-31 & 0.009 & 10.76 \\
2 & TEB & mmu-miR-17* & miR-17 & 0.019 & 7.81 \\
3 & mmu-miR-18a & miR-17 & 0.005 & 4.72 \\
4 & TEB & mmu-miR-362-5p & miR-362 & 0.027 & 4.62 \\
5 & TEB & mmu-miR-19a & miR-17 & 0.007 & 3.27 \\
1 & TEB & mmu-miR-184 & miR-184 & 0.24 \\
2 & Duct & mmu-miR-7 g* & Let-7 & 0.01 & 0.3 \\
3 & Duct & mmu-miR-1894-5p & miR-1894 & 0.028 & 0.37 \\
4 & Duct & mmu-miR-346 & miR-346 & 0.027 & 0.021 \\
\end{tabular}

$\mathrm{Tp}_{53^{-/-}}$tumours and the MMTV-Neu tumours, however, miR-184 expression in the C3 SV40 Tag and MMTV-PyMT tumours was comparable to normal mammary epithelial cells suggesting that miR-184 might be specifically silenced in certain breast cancers or that they derive from different cells of origin (Fig. 2a). In addition, we also examined miR-17 and miR-19a, in these murine tumours. Despite the known role of this microRNA cluster in oncogenesis, there was no enrichment of these two miRNAs in murine tumours when compared to the normal mammary epithelial cells (Additional file 1: Figure S1E, F).

We interrogated the relative expression of miR-31, miR-184, miR-17 and miR-19a in a panel of human breast cancer cell lines. Seven basal breast cancer cell lines comprising both basal A and basal B and five luminal cell lines were chosen to represent these breast cancer subtypes [38]. The expression of miR-31 was restricted to the basal breast cancer cell lines compared to the luminal cell lines (Additional file 1: Figure S1A). miR-17 and miR-19a were relatively evenly expressed across cell lines (Additional file 1: Figure S1B, C). Conversely, the expression of miR-184 was undetectable in a majority of cell lines with the exception of MDA-MB-175 (Fig. 2b).

miR-184 suppresses proliferation of human breast cancer cell lines in two-dimensional and suspension culture

To elucidate its function in cancer, miR-184 was acutely overexpressed in highly proliferative human breast cancer cell lines: MDA-MB-231, BT-549, MDA-MB-436 and HS578T, which express undetectable levels of endogenous levels of miR-184. Let-7a is a well-characterised tumour suppressor miRNA and has been shown to impede proliferation in cancer cell lines, and hence, was used as a positive control in this experiment. The exogenous overexpression of miR-184 resulted in levels comparable to the endogenous levels of miR-184 detected in the MDA-MB-175 (not shown). miR-184 inhibited cell proliferation significantly in all four models (Fig. 2c, d, Additional file 1: Figure S1G). The positive control let-7a also exhibited an anti-proliferative effect, which was of a similar magnitude to the result obtained with miR-184 (Fig. 2c, d).

Given the increase in expression of miR-184 as mammary epithelia differentiated in vivo, we asked whether ectopic miR-184 expression regulates the self-renewal capacity of breast cancer cells. Tumoursphere assays [39] were performed in MDA-MB-231 cells constitutively overexpressing miR-184. This assay requires cells to be in cultured in suspension for an extended period, therefore, miR-184 was overexpressed via retroviral transduction. MDA-MB-231 cells overexpressing miR-184 had a $50 \%$ reduction in tumoursphere-forming potential in primary tumourspheres as well as in secondary tumourspheres when compared to the negative control (Fig. 2e).

\section{miR-184 suppresses tumour initiation and proliferation} in vivo

After ascertaining the inhibitory effect of miR-184 on proliferation and self-renewal in vitro, we wanted to examine the role of miR-184 in vivo. Control and miR-184 overexpressing MDA-MB-231 cells were separately injected into the mammary fat pad of cohorts of immunocompromised NOD/SCID mice $(n=5)$. At 10 weeks post transplantation, primary tumours and internal organs were harvested. All the mice in the control group developed solid tumours, however, in stark contrast, none of the mice within the miR-184 cohort had developed any palpable tumours at this time point (Fig. 2f). Under detailed visual examination of the miR-184 cohort by fluorescent microscopy, a small population of GFP+ cells could be detected in the mammary gland. H\&E staining identified a bolus of miR-184 overexpressing cells localised to the injection site (Fig. 2g). These results suggested that cells overexpressing miR-184 have impaired proliferation in vivo.

We performed immunohistochemical staining on the tumour sections for phospho-histone $\mathrm{H} 3$ and scoring for 
A

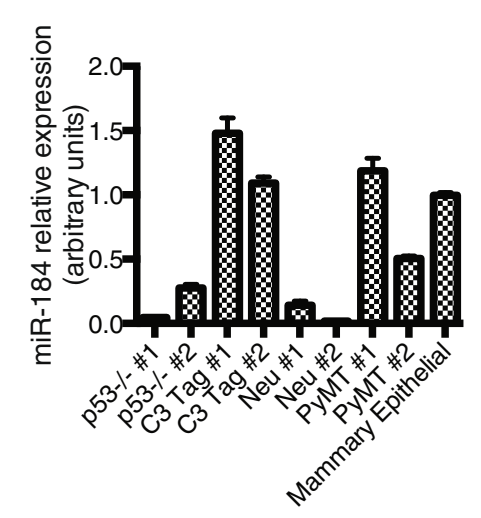

C

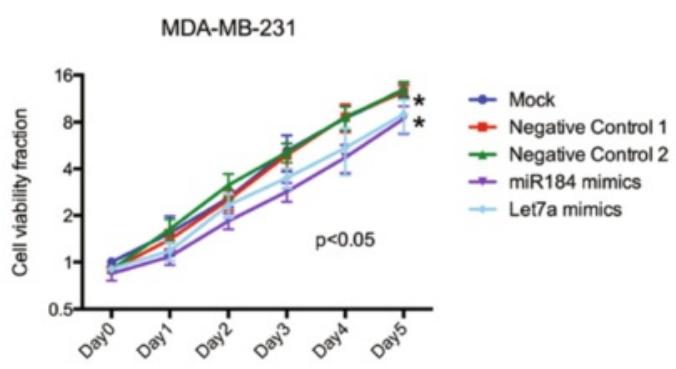

E
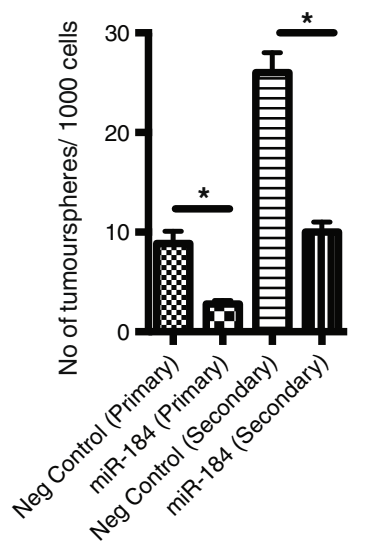

G

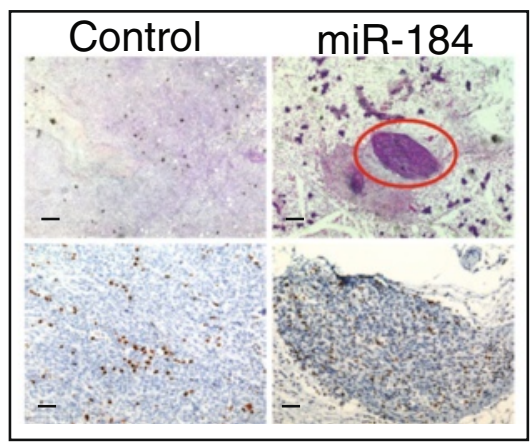

\section{B}

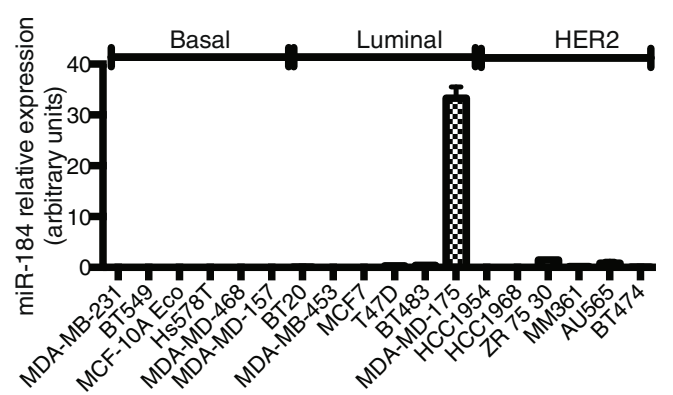

D
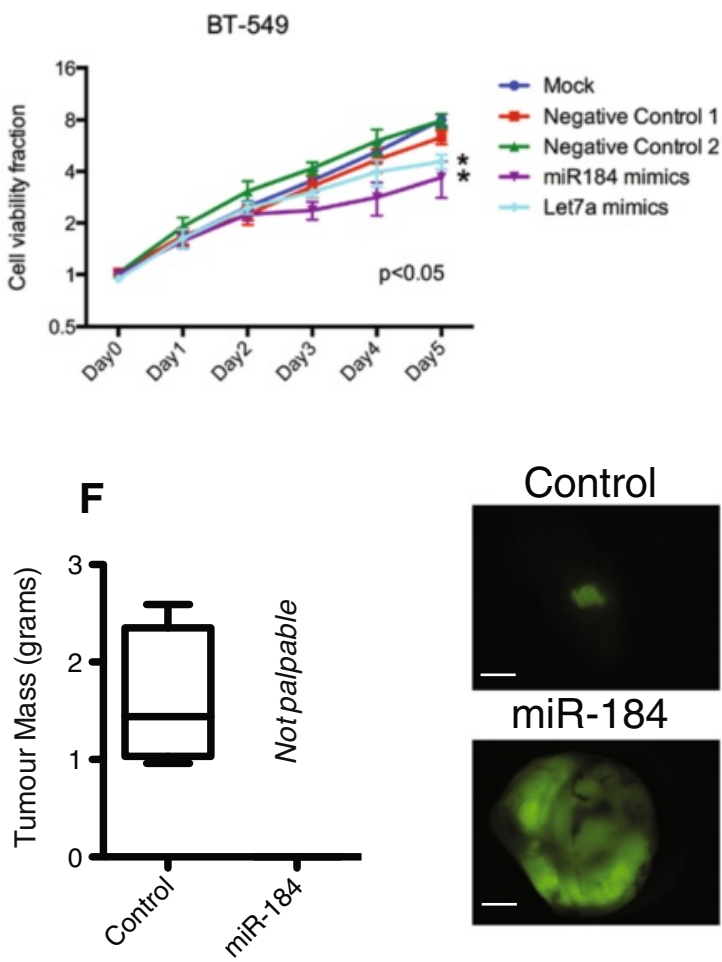

H

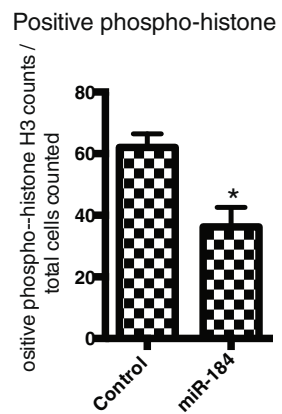

Mitotic figures

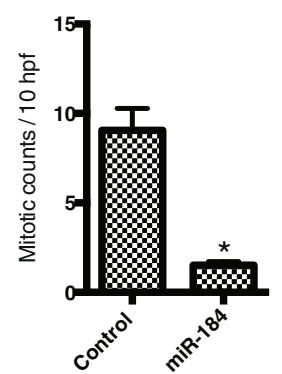

Fig. 2 (See legend on next page.) 
(See figure on previous page.)

Fig. 2 Expression of miR-184 is lost in cancer models. Ectopic expression suppresses proliferation and self-renewal in vitro and in vivo. a miR-184 expression is lost in several mouse models of breast cancer, compared to total mouse mammary epithelium. microRNA expression was normalised to SnoRNA202. b miR-184 is undetectable in a majority of human breast cancer cell lines. microRNA expression is normalised to RNU6. c MDA-MB-231 were transfected with microRNA mimics, proliferation was measured for 5 days by MTS assay. $\mathbf{d}$ BT-549 were transfected with microRNA mimics, proliferation was measured for 5 days using MTS assay. c, $\mathbf{d}$ Results are expressed as mean + standard error from three independent experiments performed in sextuple technical replicates. The $t$ test was performed: ${ }^{*} p<0.05$ indicates significant difference in proliferation in cells overexpressing miR-184 compared with non-targeting miRNA control. e MDA-MB-231 stably overexpressing miR-184 and control were cultured in low adherent plates and enumerated for primary and secondary tumourspheres. The $t$ test was performed: ${ }^{*} p<0.05$ indicates significant difference in tumoursphere-forming potential in cells overexpressing miR-184 compared to control. $\mathbf{f}$ Tumour mass in NOD/SCID mice $(n=5)$ after injection of MDA-MB-231 constitutively overexpressing miR-184, let-7a or negative control into the mammary fat pad. g Haematoxylin and eosin (H\&E) (top) and phospho-histone H3 (bottom) immunohistochemical analysis. Circle identifies focus of MDA-MB-231 cells at the injection site. Top scale bars $=50 \mu \mathrm{M}$, bottom scale bars $=30 \mu \mathrm{M}$. $\mathbf{h}$ Quantitation of phospho-histone H3 immunoreactivity and mitotic figures in tumour sections. The $t$ test was performed: ${ }^{*} p<0.05$ indicates significant difference in positive phospho-histone H3 expression and mitotic figures in miR-184 cohort compared to control cohort. HER2 human epithelial growth factor receptor 2, neg negative

mitotic figures, both of which measure actively dividing cells. A significantly lower proportion of cells overexpressing miR-184 were positive for phospho-histone H3 positive cells and mitotic figures compared to the control group (Fig. 2h), confirming the suppression of proliferation by miR-184.

\section{miR-184 expression prolongs survival and reduces metastatic burden}

We conducted a survival experiment to ascertain if miR-184 expression extended survival. Mice were transplanted with MDA-MB-231 cells expressing miR-184, Let-7a or negative control and aged to ethical endpoint. The control group developed palpable tumours as early as 24 days post transplantation, and these tumours propagated at a faster rate when compared to the miR-184 group (Fig. 3a). In contrast, there was delayed latency in tumour growth in the miR-184 group where mean time to tumour palpation was by day 38. This delay in tumour initiation was also observed in the let-7a cohort and translated to an increase in overall survival. This result suggests that miR-184 impedes tumour initiation and growth.

Lastly, we also examined if miR-184 could reduce metastatic burden in vivo. Visual examination and quantification by fluorescence microscopy at ethical endpoint was used to identify macroscopic metastases in the lung and pancreas, the most frequent sites of metastasis in this model. The majority of control mice developed multiple metastases in the lungs and pancreas. In contrast, only approximately $20 \%$ of mice within the miR-184 cohort developed any metastatic lesions in the lung ( $p=0.06)$ (Fig. 3b). In addition, we also observed a similar reduction in metastatic burden in the pancreas, where only $10 \%$ of mice from the miR-184 cohort developed any pancreatic metastases (Fig. 3c).

\section{Regulatory targets of miR-184}

Next, we aimed to identify the repertoire of miR-184 targets to explain the impact of miR-184 on proliferation. We capitalised on the evidence that miRNAs can destabilise the mRNA of their targets to use a gene-expressionbased approach to target identification [40]. We transfected miR-184 or control microRNA mimics into MDA-MB-231 breast cancer cells and analysed global gene expression changes compared to controls by affymetrix gene arrays.

We observed 1,263 mRNAs and 592 mRNAs that were significantly upregulated and downregulated respectively in cells overexpressing miR-184 compared with the negative control, suggesting dramatic remodelling of gene expression by miR-184 expression. From the profiling data, we filtered and identified the top miR-184 repressed mRNA targets based on their fold change (Table 2). AKT1S1, more commonly termed PRAS40 was the most significantly downregulated gene with approximately 3.1-fold change, followed by LAT1, which was repressed approximately 2.7 -fold. To identify direct targets of miR-184 from the profiling data, we adopted a comprehensive seed match analysis method previously described by Melton et al. [30], which interrogates the promoter, 5' UTR, CDS and 3' UTRs of transcripts downregulated following microRNA overexpression for the presence of miR-184 seed matches. The analysis revealed highly significant enrichment of miR-184 seed matches within the 5' UTR and 3' UTR regions of the downregulated transcripts, suggesting that miR-184 modulates its targets by targeting the UTRs (Fig. 4a). We did not observe any significant enrichment of miR-184 seed regions within the upregulated genes, suggesting that this method identifies bone fide direct targets.

Of the 557 downregulated genes, 193 of the genes possessed a miR-184 seed match in the UTR; of these 193 genes, 135 of them had a miR-184 seed match only in the 3' UTR, 30 genes contained a miR-184 seed match only in the $5^{\prime}$ UTR and 23 genes possessed a miR-184 seed region in both the $3^{\prime}$ and $5^{\prime}$ UTR. The remaining genes contained miR-184 binding sites in either the CDS and/or UTRs. We asked 
A

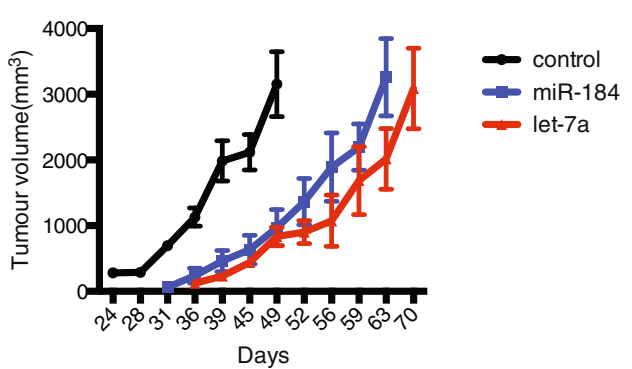

B

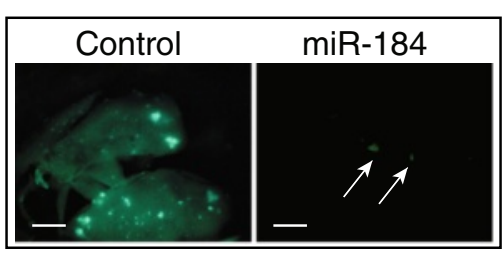

C
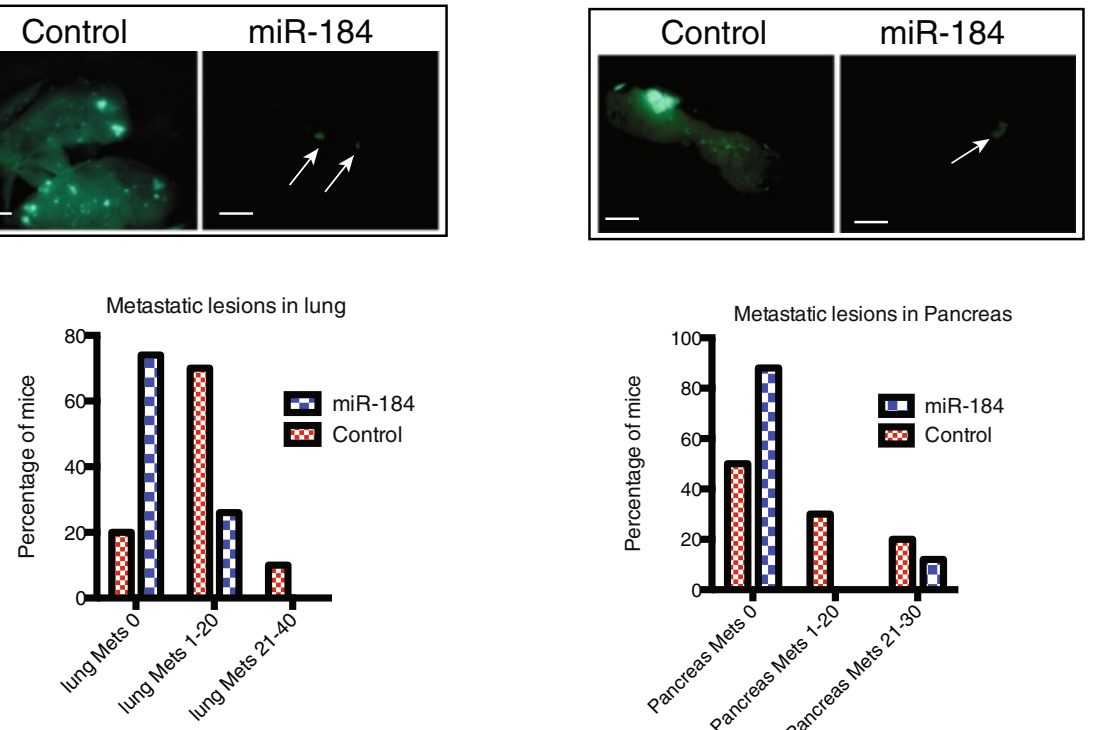

Distant metastases in lung

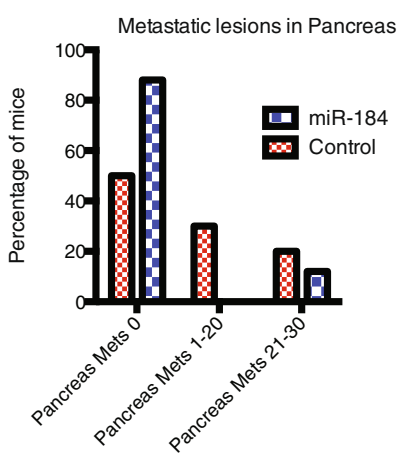

Distant metastases in pancreas
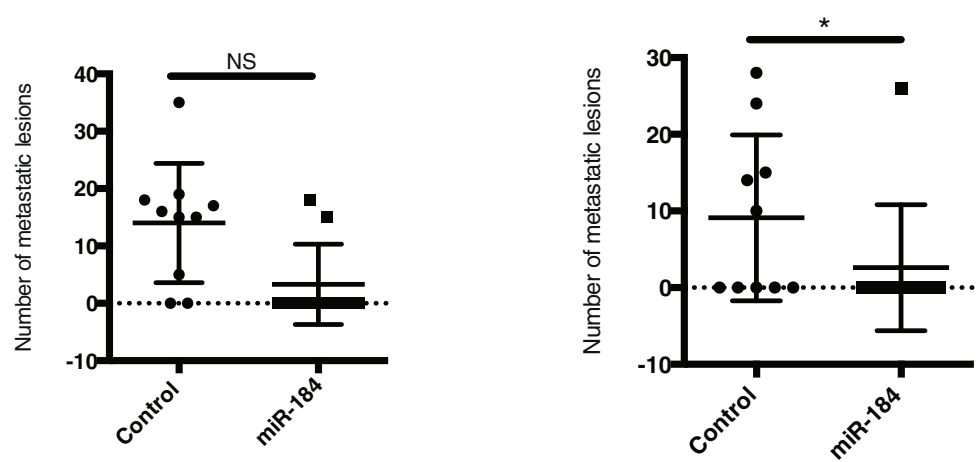

Fig. 3 miR-184 delays onset of metastases (mets) in distant organs and prolongs survival. a Growth rate of tumours after injection of MDA-MB-231 into the mammary fat pad in NOD/SCID mice ( $n=10$ per group) constitutively overexpressing miR-184, let-7a or negative control. b Representative images of micrometastases in the lung and percentage of NOD/SCID mice $(n=10)$ with $0,1-20$ or $21-40$ metastatic lesions in the lung. $\mathbf{c}$ Pancreas of control and miR-184 cohorts and percentage of NOD/SCID mice ( $\mathrm{n}=10$ ) with $0,1-20$ or 21-30 metastatic lesions in the pancreas. The $t$ test was performed; ${ }^{*} p<0.05$ indicates significant difference in the number of micrometastases in miR-184 cohort compared to control cohort. Scale bar $=200 \mu \mathrm{M}$. NS not significant

whether the number of miR-184 seed matches within the downregulated genes correlated with a greater degree of repression. Interestingly, in contrast to previous studies $[41,42]$, we observed no additive or synergistic effect on
mRNA destabilisation when multiple seed matches were detected (Additional file 2: Figure S2A). We also saw no added enrichment in repression when there was multiple miR-184 seed match regions located only in the 
Table 2 Top 30 genes significantly repressed by miR-184 $(Q<0.05)$

\begin{tabular}{|c|c|c|}
\hline Genes & Fold change & $Q$ value \\
\hline PRAS40 & 3.1092 & 0.0000887 \\
\hline SLC7A5 & 2.7426 & 0.0001686 \\
\hline CSF1 & 2.5244 & 0.00004997 \\
\hline RRP1B & 2.3603 & 0.00006787 \\
\hline SEMATA & 2.3251 & 0.0013856 \\
\hline ADAM19 & 2.3148 & 0.00003501 \\
\hline TNFSF18 & 2.3009 & 0.0005973 \\
\hline CARM1 & 2.2891 & 0.00004997 \\
\hline POM121 & 2.2415 & 0.00006787 \\
\hline SH3GLI & 2.2386 & 0.00003501 \\
\hline S100A16 & 2.2311 & 0.00003501 \\
\hline$K L C 2$ & 2.2168 & 0.00003501 \\
\hline PPAP2B & 2.1852 & 0.00007764 \\
\hline PLBD2 & 2.1415 & 0.00003501 \\
\hline CYB5R3 & 2.0392 & 0.00006787 \\
\hline LASP1 & 2.0308 & 0.00003501 \\
\hline PPP6R1 & 2.0175 & 0.00003501 \\
\hline CDC25A & 2.0013 & 0.0004932 \\
\hline PNO1 & 1.9322 & 0.0011347 \\
\hline HAS2 & 1.9214 & 0.0014053 \\
\hline SEPT9 & 1.9143 & 0.0001192 \\
\hline MYADM & 1.9084 & 0.0001448 \\
\hline PLAGL2 & 1.9068 & 0.00019 \\
\hline GSK3A & 1.902 & 0.00006787 \\
\hline AKT2 & 1.9014 & 0.00004997 \\
\hline REXO1 & 1.8962 & 0.0004027 \\
\hline FSCN1 & 1.8733 & 0.0004771 \\
\hline STK4O & 1.8697 & 0.00008406 \\
\hline IL7R & 1.8555 & 0.0064985 \\
\hline TMEM45A & 1.8489 & 0.0064985 \\
\hline
\end{tabular}

3' UTR (Additional file 2: Figure S2B) or the 5' UTR (Additional file 2: Figure S2C) or in both the $3^{\prime}$ and 5' UTR (Additional file 2: Figure S2D). Genes with miR-184 seed match in their 3' UTR were also significantly more downregulated compared to those with a miR-184 seed match in the $5^{\prime}$ UTR (Fig. 4c). These data indicate that miR-184 represses many of its mRNA targets by targeting the $3^{\prime}$ UTR and that the number of miR-184 binding sites within the 3' UTR does not correlate with degree of mRNA destabilisation.

Our analysis of putative direct targets identified at least 158 targets that are repressed and contain a 3' UTR seed match. To look for functional relationships between these putative targets, we applied gene set enrichment analysis (GSEA) [43]. There was an enrichment of genes involved in oxidative stress, PI3K/AKT signalling, apoptosis via NFKB and axon repulsion (Additional file 2: Figure S2E). We focused on the PI3K/AKT pathway for two reasons. First, AKT2 has been shown to be an miR-184 direct target in neuroblastoma [44]. Second, AKT signalling is often dysregulated in breast cancer and $A K T 2$ has been identified as a driver gene in mammary tumourigenesis [45].

Within the PI3K/AKT gene list, there was core enrichment for several genes from our profiling data (marked as yes under the core enrichment column), suggesting that the differential expression of these genes was significant (Additional file 3: Table S1). AKT2, PRAS40 and GSK3A were immunoblotted to validate the microarray result. There was a marked reduction in the total protein expression of AKT2, PRAS40 and GSK3A when miR-184 was overexpressed (Fig. 4d). In order to ascertain whether these genes were targets of miR-184, HEK293T cells were transfected with miR-184 or negative control in combination with 3' UTR luciferase reporters for CSF1, GSK3A, AKT2 or PRAS40 in addition to ITGB1 (used as a negative control) and a construct containing perfect matches to the miR-184 sequence as a positive control (PMR). There was no repression in the luciferase activity of ITGB1 and a near complete ablation in luciferase activity of the PMR. We observed robust repression (>50\%) in the luciferase activity of reporters carrying the 3' UTR from CSF1, GSK3A, AKT2 and PRAS40 signifying that miR-184 expression can act via the 3' UTR to destabilise the mRNA of these targets (Fig. 4e).

\section{miR-184 targets AKT/mTOR protein synthesis pathway}

$\mathrm{AKT}$ is a central node for orchestrating myriad pro-survival and proliferative pathways in oncogenesis [46]. One such downstream effector pathway is the mTOR signalling cascade. The mTOR pathway consists of two mTOR complexes, mTORC1 and mTORC2. The mTORC1 complex comprises RAPTOR, mLST8 and PRAS40 and when activated, initiates cell growth, proliferation and protein synthesis by regulating S6K1 and 4E-BP1 [47]. From the GSEA, there was enrichment for targets genes such as TSC2, RPS6KB2, implicated in mTORC1 mediated protein synthesis in cells overexpressing miR-184, and hence, we asked if miR-184 could be an important regulator of $\mathrm{AKT} / \mathrm{mTORC} 1$ protein synthesis pathway.

We transfected MDA-MB-231 cells with miR-184 mimics, serum starved them and stimulated the cells with EGF, which is known to initiate a cascade of signalling events to promote cell proliferation, growth and survival. As expected, there was a marked decrease in total AKT2 and PRAS40 expression in cells overexpressing miR-184 and no change in the total protein expression of AKT1 and AKT3. Interestingly, miR-184 also decreased the total protein expression of mTOR (Additional file 4: Figure S3A). In control cells treated with EGF, we observed activation of 


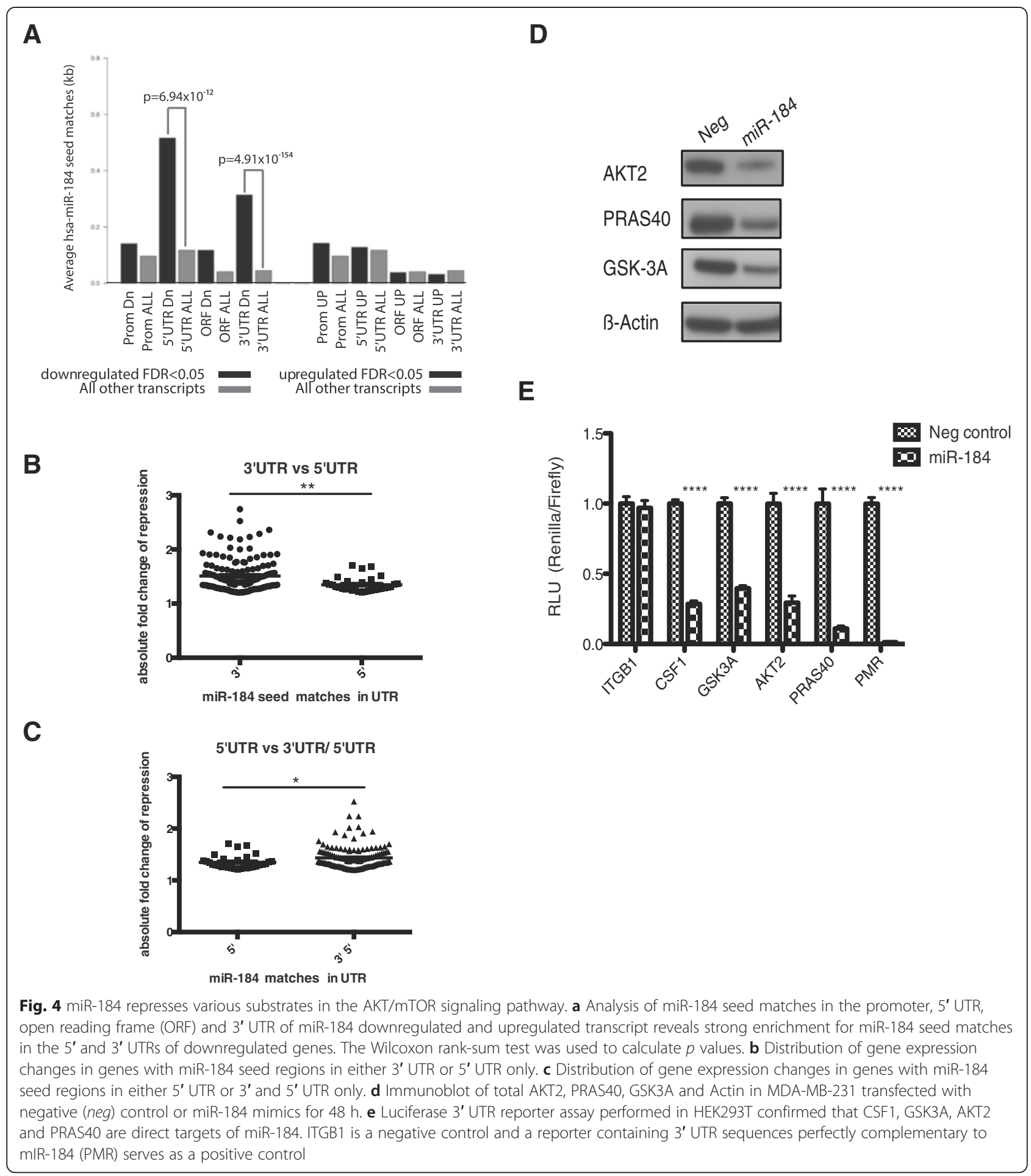

AKT as both Ser473 and Thr308 were phosphorylated (Fig. 5a). In return, activated AKT inhibited the activities of TSC2 and PRAS40 through phosphorylating them at Thr1462 and Thr246 respectively (Fig. 5a), thus initiating the activation of mTORC1. Conversely when cells overexpressing miR-184 were treated with EGF, we observed a modest increase in p-AKT Thr308, indicating that there was increased AKT activity. Despite the increased AKT activity, the inhibition on TSC2 was completely abrogated, as observed from the dephosphorylation of Thr1462, possibly by miR-184 targeting AKT2. Finally the activating phosphorylation of S6K1 at Threonine-389, a rate-limiting 


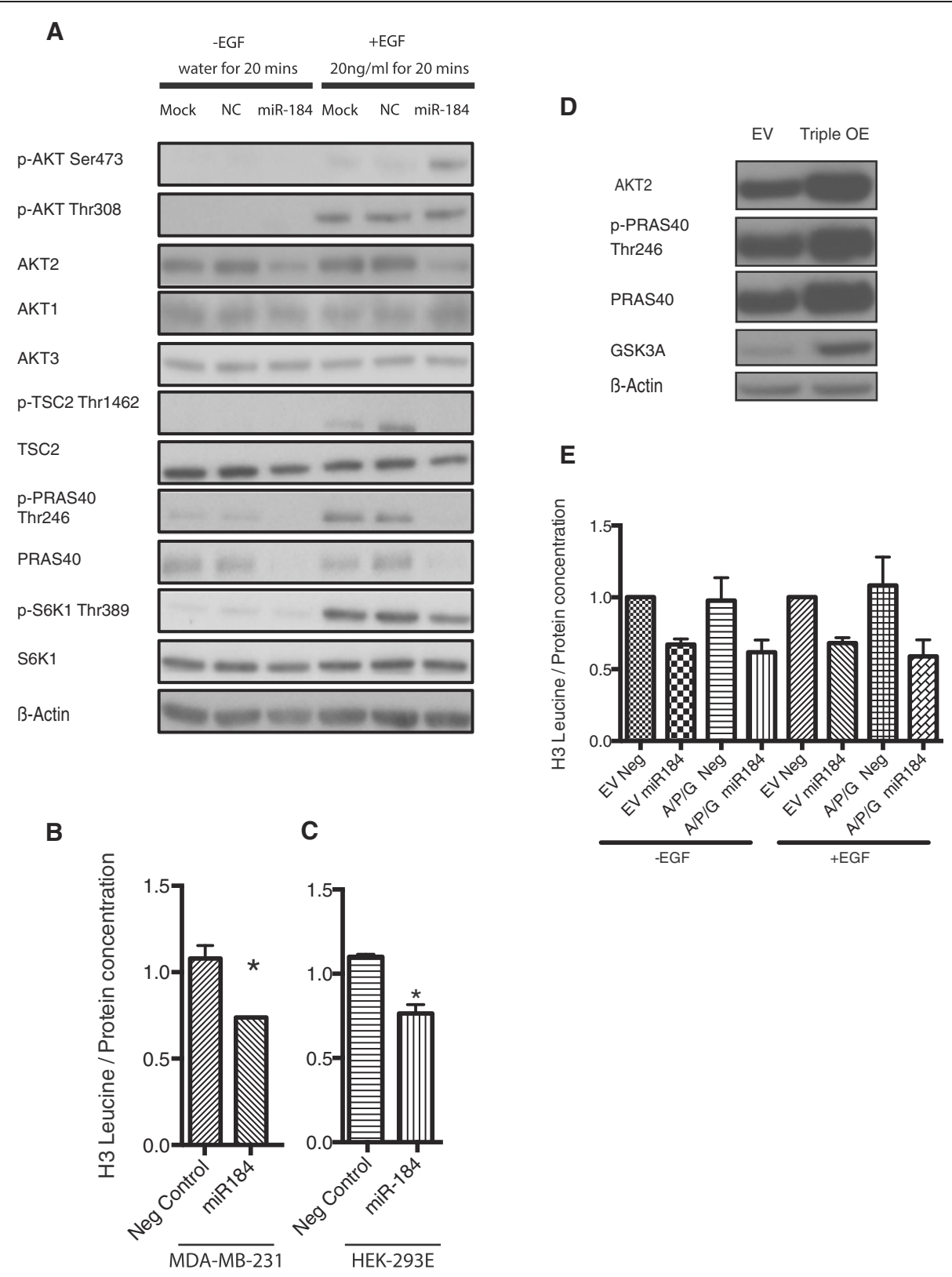

Fig. 5 miR-184 suppresses protein synthesis by negatively regulating AKT/mTORC1 pathway. a Immunoblots of members of the AKT/mTOR pathway in MDA-MB-231 transfected with miR-184 mimics and treated with and without epidermal growth factor (EGF). b Measurement of protein synthesis by using B-Scintillation in MDA-MB-231 transfected with negative control or miR-184 mimics for 24 h, serum starved overnight and treated with labelled H3 leucine. c Measurement of protein synthesis by using B-Scintillation in HEK293E transfected with negative control or miR-184 mimics for $24 \mathrm{~h}$, serum starved overnight and treated with labelled H3 leucine. $\mathbf{d}$ Western blot confirming overexpression of AKT2, PRAS40 and GSK3A. e Protein synthesis in cells overexpressing AKT2 (a), PRAS40 (P) and GSK3A or control (empty vector, EV), transfected with miR-184 mimics (184) or controls (Neg)

factor in protein synthesis, was attenuated without affecting the activity of 4E-BP1 (Additional file 4: Figure S3A).

We also further examined if this miR-184-regulated signalling cascade was recapitulated in vivo. Within the cohort of mice bearing miR-184-overexpressing tumour cells, the expressions of a number of miR-184 targets (e.g., AKT2, GSK3A and S6K2) were reduced in three out of four mice when compared to the control tumours. Furthermore, we also observed a dramatic repression of mTOR expression accompanied by the dephosphorylation of S6K1 indicating a partial attenuation of the protein synthesis pathway (Additional file 4: Figure S3B).

To directly assay the impact of EGF stimulation and miR-184 expression on protein synthesis, we transfected 
MDA-MB-231 cells with the miR-184 mimics, and measured the amount of protein synthesised in the cell by incorporating radiolabelled tritiated $\left(\mathrm{H}^{3}\right)$ leucine into cells in the presence of EGF. miR-184 repressed global protein synthesis dramatically (Fig. 5 b). In order to demonstrate that this regulatory phenomenon exhibited by miR-184 was not restricted to the MDA-MB-231 model, we performed the same assay with the HEK293E cells using another growth factor, insulin. We detected that miR-184 similarly repressed global protein synthesis by approximately $30 \%$ in the HEK293E cells stimulated with insulin (Fig. 5c).

\section{Overexpression of AKT2, PRAS40 or GSK3A does not rescue miR-184 repression of protein synthesis}

We were interested to see if we could reverse the repression on protein synthesis by overexpressing some of the core enriched top candidate genes identified from the GSEA. Therefore we tested if direct targets AKT2, PRAS40 or GSK3A were responsible for the effect of miR-184 on MDA-MB-231 cell protein synthesis by stably overexpressing AKT2, PRAS40 and GSK3A individually or in combination, together with transfection of miR-184 or negative control mimics. Despite the overexpression of these direct target genes individually (Additional file 5: Figure S4A, B, C) or in combination (Fig. 5d, e), protein synthesis was nonetheless suppressed by miR-184 expression in these cell lines. These results suggest that miR-184 regulates the protein synthesis process by modulating expression of genes in addition to AKT2, PRAS40 and GSK3A.

\section{miR-184 expression and prognostic significance in breast cancer}

We next investigated the significance of miR-184 expression in breast cancer and its association with clinicopathological measures. We measured miR-184 expression in snap-frozen primary tumour specimens comprising patient samples diagnosed with luminal, HER2-amplified and triple negative cancers and matched normal tissue. We observed unique expression patterns for miR-184 across these subtypes. There were no significant differences in the expression of miR-184 between luminal cancers and matched normal. However within the HER2 subtype, the patients fell into two groups: normal-like and high miR-184 expression. Last, miR-184 expression was significantly lower in the triple negative subtype compared to the matched normal (Fig. 6a). To verify this result in a bigger patient cohort, we analysed miR-184 expression in the METABRIC cohort of 980 breast cancers [31] and also observed that miR-184 mean expression was highest in HER2-positive breast cancers and significantly lower in basal breast cancers, a subset of TNBC (Fig. 6b). In this cohort, miR-184 expression did not correlate with prognosis (data not shown). However, elevated expression of a signature composed of high-confidence direct targets of miR-184 predicted poor overall survival (Fig. 6c). This effect was observed in two further independent cohorts (Additional file 6: Figure S5). In multivariate analysis, this signature predicted poor prognosis independent of ER status in two out of three cohorts (Additional file 7: Table S2). These data are consistent with a role for miR-184 in suppressing proliferation or metastatic dissemination.

\section{miR-184 is epigentically silenced in human cancers}

There is emerging evidence for epigenetic silencing by hypermethylation [48] of miRNAs with tumour suppressor properties or growth inhibitory functions in various malignancies [49-52]. Methyl-capture sequencing was performed to capture a global snapshot of the genomewide DNA methylation profile of normal mammary tissue, primary TNBC tumours and matched metastatic tumours micro-dissected from the lymph nodes of patients. We observed that there was minimal methylation detected at the miR-184 locus in normal breast tissue. In contrast, there was a pronounced increase in methylation in metastatic tumours in the lymph nodes of three of eight patients (Fig. 6d), suggesting a selective pressure to silence miR-184 during metastatic dissemination, consistent with the capacity of miR-184 to suppress metastasis in animal models (Fig. 3).

\section{Discussion}

In our study, we have discovered miRNAs enriched in different subcellular compartments of the developing mammary ductal structure. These results suggest that some miRNAs are expressed in specific subcellular compartments, such as the TEBs and mature ducts, to modulate cellular processes such as proliferation and differentiation during ductal elongation. We then asked, however, if these miRNAs were differentially expressed and functional in cancer. As a proof of concept, we found TEB-enriched miRNAs to be highly expressed in a panel of breast cancer models whereas miRNAs enriched in the ducts displayed an opposite trend, being lowly expressed in cancer.

One of the miRNAs that followed this expression pattern was miR-184. Upon functional characterisation, there was compelling evidence to suggest that miR-184 is a tumour suppressor in certain cancer subtypes, as it suppressed cell proliferation and self-renewal in vitro and tumour growth in the primary and distant sites. A role in modulating metastasis is supported by analysis of a subset of TNBC patient samples, where miR-184 was epigenetically silenced in lymph node metastases, suggesting silencing of miR-184 can promote metastatic dissemination. Upon interrogating a large breast 
A
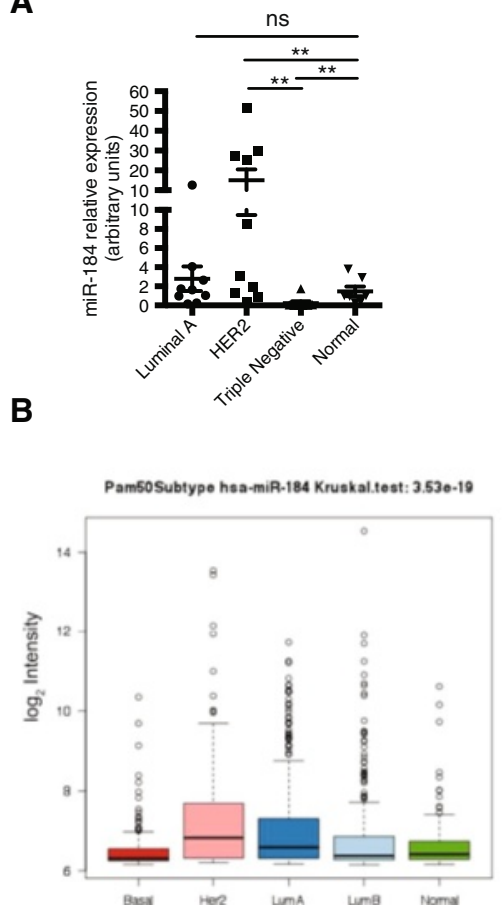

D

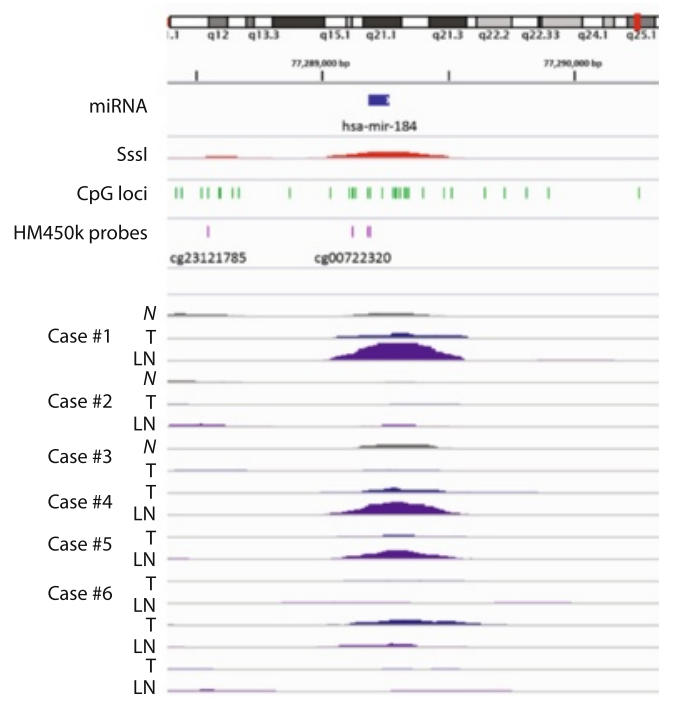

C

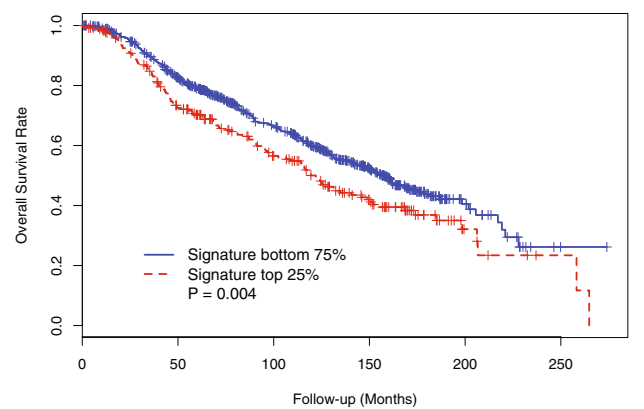

Fig. 6 miR-184 is downregulated in triple negative breast cancer, methylated in metastatic lesions and reduced expression of stringent miR-184 targets correlates with poor overall survival in breast cancer patients. a miR-184 expression in luminal A, human epidermal growth factor (HER2), triple negative and matched normal tissue. The $t$ test was performed: ${ }^{*} p<0.05,{ }^{* *} p<0.01$. b Analysis of miR-184 expression in the Molecular Taxonomy of Breast Cancer International Consortium (METABRIC) patient cohort stratified by intrinsic subtype: $p<1 \times 10^{-18}$. c Kaplan-Meier survival analysis comparing the outcome of METABRIC patients stratified by signature score of miR-184 repressed targets (red, samples with top $25 \%$ signature score $(n=246)$; blue, samples with bottom $75 \%$ signature score $(n=734))$. Overall survival was used as the outcome metric. d The miR-184 locus is hypermethylated in some metastatic lymph node biopsies (LN) when compared to primary tumour ( $T$ ) and normal breast tissue (N). SssI MBD2IP (red) has been treated with methylase and acts as a positive control for methylation at this locus

cancer cohort (METABRIC) dataset, we also observed a significant decrease in miR-184 expression in the ER-negative tumours compared to the ER-positive tumours. In this cohort, very few microRNAs associate with prognosis [53], as we found for miR-184. However, elevated expression of high-confidence targets repressed by miR-184 predicted poor prognosis, consistent with our evidence from animal models that elevated miR-184 activity improves outcome.
miR-184 is crucial in regulating certain developmental processes such as the differentiation of neural stem cells, germ line cells and corneal epithelial cells [54-56]. Several studies have established that miR-184 is lowly expressed in different malignancies such as childhood neuroblastoma, brain cancers, clear cell renal cell carcinoma and prostate cancer [44, 57-60]. When miR-184 was ectopically overexpressed in vitro, it resulted in cell cycle arrest and apoptosis [44, 57, 58], 
as well as impeding neuroblastoma xenograft formation resulting in longer survival in vivo [61]. Though several downstream targets of miR-184 such as AKT2, NUMBL, SHIP2, NFAT1 have been identified in different cell types, nevertheless there have been no definite reports on the functional role of miR-184 in breast cancer nor detailed analysis of signalling pathways that are potentially modulated by miR-184 [44, 54, 62, 63].

miR-184 has been previously shown to be controlled by epigenetic mechanisms in development. This was identified in the mouse brain, where the genomic region proximal to the miR-184 locus in adult neural stem cells contains CpG rich sequences instead of canonical CpG islands. Methyl-CpG binding protein 1 (Mbd1) binds to these CpG-rich sequences in the genomic regions surrounding miR-184, and represses the transcriptional activity of miR-184 [54]. In a separate study, researchers performed bisulphite sequencing on umbilical cord blood graft CD4+ $\mathrm{T}$ cells and discovered a small putative CpG island just upstream of the miR-184 locus, and an additional $32 \mathrm{CpG}$ sites present within the adjacent regions of the miR-184 locus making it an ideal target for epigenetic silencing [63].

We are the first to provide evidence to suggest that the attenuated expression of miR-184 in cancer is potentially a result of epigenetic mechanisms. miR-184 was methylated in a subset of lymph node metastases in TNBC, providing supportive evidence that miR-184 may play a role as a novel mammary tumour suppressor. We hypothesised that the methylation of miR184 in metastatic tissue suggests a selective pressure against maintenance of miR-184 particularly during metastatic dissemination.

Our experimental evidence suggests that the antitumourigenic properties displayed by miR-184 are a consequence of miR-184 inhibiting the activity of the $\mathrm{PI} 3 \mathrm{~K} / \mathrm{AKT} / \mathrm{mTORC} 1$ pathway, therefore limiting protein synthesis. This study suggests that miR-184 suppresses the protein synthesis pathway by targeting several important members of the AKT/mTOR pathway. miR-184 represses the total levels of AKT2, which relieves the inhibitory function on TSC2, the crucial negative regulator of the mTORC1 pathway. In addition, the reactivation of $\mathrm{TSC} 2$ results in the abrogation of S6K1 activity, the effector of the protein synthesis pathway.

Furthermore, this signalling event was partially recapitulated in vivo, where miR-184 repressed several substrates within the $\mathrm{AKT} / \mathrm{mTORC1}$ pathway in a majority of tumours. The total expression of mTOR was reduced in the miR-184 cohort, potentially inhibited the formation of the mTORC1 and therefore reducing the activity of S6K1. Interestingly, we also observed a loss of TSC2 expression and an increase in PRAS40 expression in the
miR-184 cohort. It is possible that these changes are compensation to circumvent the anti-proliferative effects of miR-184 during tumour progression.

These changes in the signalling pathway correlate with our protein synthesis assay, where we observe less synthesised proteins in cells overexpressing miR-184. However, we do not fully comprehend how miR-184 suppresses protein synthesis. Despite the overexpression of AKT2, PRAS40 and GSK3A in combination, we were unable to rescue the miR-184 mediated suppression of protein synthesis and hence more work needs to be conducted to define the rate limiting targets in protein synthesis and proliferation downstream of miR-184.

Several other targets may explain this phenotype. S6K2, a member of $40 \mathrm{~S}$ ribosomal protein $\mathrm{S} 6$ kinase family was also repressed by miR-184 at the mRNA and protein level. The 40S ribosomal S6 kinase is a direct substrate of mTORC1 signalling, and when activated it drives cell growth and proliferation by recruiting translational machineries and initiating protein production in cells [64]. Even though S6K2 is homologous to S6K1, sharing $83 \%$ identical amino acid sequences, they both display unique functions $[65,66]$.

CSF1 and LAT1 were also significantly repressed when miR-184 was overexpressed. Evidence in the literature associates both genes with promoting tumourigenesis and metastasis [67-77]. LAT1 also plays an important role in transporting available amino acids into the cell for protein synthesis, which provides a possible explanation for the inability to revert the defect in protein synthesis even by the overexpression of AKT2, PRAS40 and GSK3A.

As the PI3K/AKT/mTOR axis is such a crucial signalling axis in mediating a myriad of cellular functions essential in both normal development and during carcinogenesis, many research groups have focussed on elucidating the convoluted regulation of these pathways. In recent years, studies have revealed that there is a landscape of microRNAs that specifically regulate various components of the PI3K/AKT/mTOR signalling axis in orchestrating a series of fundamental cellular processes in normal development; including stem cell expansion [78], wound healing [79] and smooth muscle and pancreatic beta cell proliferation $[80,81]$.

\section{Conclusions}

We propose that miR-184 mimics the role of a capacitor to control signalling current through the PI3K-mTOR pathway in the presence of a stimulus by targeting intermediates of the AKT/mTOR cascade and in turn tuning the signalling output. Integration of miR-184 expression and activity in PI3K-AKT-mTOR pathway analysis may help better predict pathway dynamics and response to therapeutics targeting this pathway. 


\section{Additional files}

Additional file 1: Figure S1. Validation of differential microRNA expression and additional human cell line transfections. miR-31 (A) miR-17 (B) and miR-19a (C) expression in a panel of breast cancer cell lines. microRNA expression was normalised to RNU6. miR-31 (D), miR-17 (E), and miR-19a (F) expression in murine tumour models. microRNA expression was normalised to SnoRNA202 (G0 miR-184 suppresses proliferation in MDA-MB-436 and HS578T cells in vitro. Graphs depict the mean $+/-$ standard error of the mean of three independent experiments; ${ }^{*} p<0.05$.

Additional file 2: Figure S2. MicroRNA target identification. A Total number of miR-184 seed matches in the promoter, 5' UTR, open reading frame (ORF) and 3' UTR of downregulated transcripts. B Total number of miR-184 seed matches present only in the 3' UTR of downregulated transcripts. C Total number of miR-184 seed matches present only in the 5'UTR of downregulated transcripts. D Total number of miR-184 seed matches present only in both 3' and 5' UTR of downregulated transcripts. E Gene set enrichment analysis of miR-184. Enrichment plots and statistics are shown for the nine most significantly (false discovery rate $<0.05$ ) downregulated gene sets involved in oxidative stress, trabectedin resistance, PI3K/AKT, apoptosis via NFKB, and axon repulsion.

Additional file 3: Table S1. miR-184 modulates the activity of a number of gene targets within the PI3K/AKT pathway. Core enrichment of gene targets potentially regulated by miR-184 is represented by Yes under the core enrichment column.

Additional file 4: Figure S3. miR-184 suppresses protein synthesis by negatively regulating certain substrates in AKT/mTORC1 pathway. A Immunoblots of members of AKT/mTOR pathway in MDA-MB-231 transfected with miR-184 mimics and treated with and without epidermal growth factor (EGF). B Immunoblots of members of AKT/mTOR pathway in primary tumour lysates derived from xenografts of mDA-MB-231 cells overexpressing miR-184 or control, harvested at ethical end point.

Additional file 5: Figure S4. Overexpression of miR-184 direct targets does not rescue the suppression of protein synthesis. Measurement of protein synthesis by using B-scintillation in MDA-MB-231 cells overexpressing AKT2 (A), PRAS40 (B), GSK3A (C) or in combination transfected with negative control or miR-184 mimics for $24 \mathrm{~h}$, serum starved and treated with labelled $\mathrm{H} 3$ leucine in the absence and presence of epidermal growth factor $(E G F)$.

Additional file 6: Figure S5. Reduced expression of stringent miR-184 targets correlates with poor overall survival in two independent cohorts of breast cancer patients. Kaplan-Meier survival analysis comparing outcome of patients stratified by signature score of miR-184 repressed targets. Red: samples with top $25 \%$ signature score; blue: samples with bottom $75 \%$ signature score. Overall survival was used as the outcome metric. A Molecular Taxonomy of Breast Cancer International Consortium (METABRIC) validation cohort ( $\mathrm{n}=248$ (red), $\mathrm{n}=745$ (blue). B Cohort from Hatzis et al. [31], $n=128$ (red), $n=380$ (blue).

Additional file 7: Table S2. Univariate and multivariate analysis of prognostic associations for miR184 signature.

\section{Abbreviations}

ATCC: American type culture collection; BCA: bicinchoninic acid; bFGF: bovine fibroblast growth factor; CDNA: complementary deoxyribonucleic acid; CDS: coding sequence; CSF1: colony stimulating factor 1; DMEM: Dulbecco's modified Eagle's medium; EGF: epidermal growth factor; ER: estrogen receptor; FBS: fetal bovine serum; GATA-3: GATA binding protein 3; GEO: Gene expression omnibus; GSEA: gene set enrichment analysis; GSK3A: glycogen synthase kinase 3A; H\&E: haematoxylin and eosin; HER2: human epidermal growth factor 2; ITGB1: integrin B1; MBD: methyl-CpG-binding domain; METABRIC: Molecular Taxonomy of Breast Cancer International Consortium; miRNA: MicroRNA; mLST8: mammalian lethal with Sec13 protein 8; MMTV: mouse mammary tumour virus; mRNA: messenger RNA; mTORC1: mechanistic target of rapamycin complex; NOD: non-obese diabetic; ORF: open reading frame; PBS: phosphate-buffered saline; PCR: polymerase chain reaction; PI3K: phosphatidylinositol 3-kinase; PIK3CA: phosphatidylinositol-4,5-bisphosphate 3-kinase, catalytic subunit alpha; PR: progesterone receptor; PRAS40: proline rich AKT substrate 40 kDa; PTEN: phosphatase and tensin homologue; PyMT: polyoma middle T-antigen; qPCR: quantitative polymerase chain reaction; RIPA: radioimmune precipitation assay; RNU6B: RNA, U6 small nuclear; RPS6KB1: ribosomal protein $\mathrm{S} 6$ kinase, $70 \mathrm{kDa}$, polypeptide 1; RTK: receptor tyrosine kinases; rtTA: reverse tetracycline transactivator; SCID: severe combined immunodeficiency; SLC7A5: solute carrier family 7 (amino acid transporter light chain, L system), member 5; TCA: trichloroacetic acid; TEBs: terminal end buds; TNBC: triple negative breast cancer; TSC1/2: tuberous sclerosis 1/2; UTR: untranslated region; VCB: Victoria Cancer Biobank.

\section{Competing interests}

The authors declare that they have no competing interests.

\section{Authors' contributions}

AS and YP conceived, designed and interpreted experiments and drafted the manuscript. DEJ, IN, SOT, SJC, YP, AN, JY, AM, RN, EZ, ST and HKM conceived and/or conducted and interpreted experiments and contributed to writing and review of the manuscript. DR, BE, RR, EZ, WK, ND and MC conceived and conducted bioinformatics analysis and contributed to writing and review of the manuscript. All authors read and approved the paper before submission and agree to be accountable for all aspects of the work.

\section{Acknowledgements}

This work was supported by funding from the National Breast Cancer Foundation Australia, Cancer Council NSW, Cancer Institute NSW and by generous support from the Estate of the Late R.T. Hall, CBP lawyers and John and Deborah McMurtrie. Tissues and samples were received from the Australia Breast Cancer Tissue Bank which is generously supported by the National Health and Medical Research Council of Australia, The Cancer Institute NSW and the National Breast Cancer Foundation. This study makes use of data generated by the Molecular Taxonomy of Breast Cancer International Consortium. Funding for the project was provided by Cancer Research UK and the British Columbia Cancer Agency Branch. The authors would like to acknowledge Gillian Lehrbach for providing technical assistance.

\section{Author details}

${ }^{1}$ The Kinghorn Cancer Centre \& Cancer Research Division, Garvan Institute of Medical Research, 370 Victoria Street, Darlinghurst, NSW, Sydney, Australia. ${ }^{2}$ St Vincent's Clinical School, Faculty of Medicine, Sydney, UNSW, Australia. ${ }^{3}$ Cancer Research UK Cambridge Institute, University of Cambridge, Li Ka Shing Centre, Robinson Way, Cambridge, UK. ${ }^{4}$ Department of Tissue Pathology and Diagnostic Oncology, Royal Prince Alfred Hospital, Camperdown, NSW, Australia. ${ }^{5}$ Sydney Medical School, The University of Sydney, Camperdown, NSW, Australia. ${ }^{6}$ Metabolism in Human Diseases Unit, Institute of Molecular and Cell Biology, A*STAR, 61 Biopolis Drive, Proteos, Singapore. ${ }^{7}$ The Charles Perkins Centre, School of Molecular Bioscience, University of Sydney, Camperdown, NSW, Australia. ${ }^{8}$ Agensys, affiliate of Astellas Pharmaceuticals, 1800 Stewart St, Santa Monica, CA 90403, USA

Received: 16 October 2014 Accepted: 28 May 2015

Published online: 13 June 2015

\section{References}

1. Siegel R, Naishadham D, Jemal A. Cancer statistics, 2012. CA Cancer J Clin. 2012:62:10-29.

2. Bonneterre J, Roché $H$, Monnier $A$, Guastalla JP, Namer M, Fargeot $P$, et al. Docetaxel vs 5-fluorouracil plus vinorelbine in metastatic breast cancer after anthracycline therapy failure. Br J Cancer. 2002;87:1210-5.

3. Pusztai $L$, Wagner $P$, Ibrahim N, Rivera $E$, Theriault $R$, Booser $D$, et al. Phase II study of tariquidar, a selective P-glycoprotein inhibitor, in patients with chemotherapy-resistant, advanced breast carcinoma. Cancer. 2005;104:682-91.

4. Perez EA, Lerzo G, Pivot X, Thomas E, Vahdat L, Bosserman L, et al. Efficacy and safety of ixabepilone (BMS-247550) in a phase II study of patients with advanced breast cancer resistant to an anthracycline, a taxane, and capecitabine. J Clin Oncol. 2007;25:3407-14.

5. Rakha EA, Reis-Filho JS, Ellis IO. Basal-like breast cancer: a critical review. J Clin Oncol. 2008;26:2568-81.

6. Samuels Y, Wang Z, Bardelli A, Silliman N, Ptak J, Szabo S, et al. High frequency of mutations of the PIK3CA gene in human cancers. Science. 2004;304:554. 
7. Marty B, Maire V, Gravier E, Rigaill G, Vincent-Salomon A, Kappler M, et al. Frequent PTEN genomic alterations and activated phosphatidylinositol 3-kinase pathway in basal-like breast cancer cells. Breast Cancer Res. 2008;10:R101.

8. López-Knowles E, OToole SA, McNeil CM, Millar EKA, Qiu MR, Crea P, et al. PI3K pathway activation in breast cancer is associated with the basal-like phenotype and cancer-specific mortality. Int J Cancer. 2010;126:1121-31.

9. Lehmann BD, Bauer JA, Chen X, Sanders ME, Chakravarthy AB, Shyr Y, et al. Identification of human triple-negative breast cancer subtypes and preclinical models for selection of targeted therapies. J Clin Invest. 2011;121:2750-67.

10. Fabian MR, Sonenberg N. The mechanics of miRNA-mediated gene silencing: a look under the hood of miRISC. Nat Struct Mol Biol. 2012;19:586-93.

11. Kanellopoulou C, Muljo SA, Kung AL, Ganesan S, Drapkin R, Jenuwein T, et al. Dicer-deficient mouse embryonic stem cells are defective in differentiation and centromeric silencing. Genes Dev. 2005;19:489-501.

12. Neilson JR, Zheng GXY, Burge $C B$, Sharp PA. Dynamic regulation of miRNA expression in ordered stages of cellular development. Genes Dev. 2007:21:578-89.

13. Chen C-Z, Li L, Lodish HF, Bartel DP. MicroRNAs modulate hematopoietic lineage differentiation. Science. 2004:303:83-6.

14. Ivey KN, Muth A, Arnold J, King FW, Yeh R-F, Fish JE, et al. MicroRNA regulation of cell lineages in mouse and human embryonic stem cells. Cel Stem Cell. 2008;2:219-29.

15. Lu J, Guo S, Ebert BL, Zhang H, Peng X, Bosco J, et al. MicroRNA-mediated control of cell fate in megakaryocyte-erythrocyte progenitors. Dev Cell. 2008; 14:843-53.

16. Zhao Y, Ransom JF, Li A, Vedantham V, von Drehle M, Muth AN, et al. Dysregulation of cardiogenesis, cardiac conduction, and cell cycle in mice lacking miRNA-1-2. Cell. 2007;129:303-17.

17. Lynn FC, Skewes-Cox P, Kosaka Y, McManus MT, Harfe BD, German MS MicroRNA expression is required for pancreatic islet cell genesis in the mouse. Diabetes. 2007;56:2938-45.

18. Dong J, Jiang G, Asmann YW, Tomaszek S, Jen J, Kislinger T, et al. MicroRNA networks in mouse lung organogenesis. PLoS One. 2010;5, e10854

19. Huang Q, Gumireddy K, Schrier M, le Sage C, Nagel R, Nair S, et al. The microRNAs miR-373 and miR-520c promote tumour invasion and metastasis. Nat Cell Biol. 2008;10:202-10.

20. Mu P, Han Y-C, Betel D, Yao E, Squatrito M, Ogrodowski P, et al. Genetic dissection of the miR-17 92 cluster of microRNAs in Myc-induced B-cell lymphomas. Genes Dev. 2009;23:2806-11.

21. Gregory PA, Bert AG, Paterson EL, Barry SC, Tsykin A, Farshid G, et al. The miR-200 family and miR-205 regulate epithelial to mesenchymal transition by targeting ZEB1 and SIP1. Nat Cell Biol. 2008;10:593-601.

22. Valastyan S, Reinhardt F, Benaich N, Calogrias D, Szász AM, Wang ZC, et al. A pleiotropically acting microRNA, miR-31, inhibits breast cancer metastasis. Cell. 2009:137:1032-46.

23. Ma L, Young J, Prabhala H, Pan E, Mestdagh P, Muth D, et al. miR-9, a MYC/ MYCN-activated microRNA, regulates E-cadherin and cancer metastasis. Nat Cell Biol. 2010;12:247-56.

24. Russo J, Russo IH. Susceptibility of the mammary gland to carcinogenesis. II. Pregnancy interruption as a risk factor in tumor incidence. Am J Pathol. 1980;100:497-512.

25. Dulbecco R, Henahan M, Armstrong B. Cell types and morphogenesis in the mammary gland. Proc Natl Acad Sci U S A. 1982;79:7346-50.

26. Ewald AJ, Brenot A, Duong M, Chan BS, Werb Z. Collective epithelial migration and cell rearrangements drive mammary branching morphogenesis. Dev Cell. 2008;14:570-81.

27. Kouros-Mehr H, Slorach EM, Sternlicht MD, Werb Z. GATA-3 maintains the differentiation of the luminal cell fate in the mammary gland. Cell. 2006;127:1041-55.

28. Kouros-Mehr H, Bechis SK, Slorach EM, Littlepage LE, Egeblad M, Ewald AJ, et al. GATA-3 links tumor differentiation and dissemination in a luminal breast cancer model. Cancer Cell. 2008:13:141-52.

29. Bowtie short-read aligner. http://bowtie-bio.sourceforge.net/index.shtml.

30. Melton C, Judson RL, Blelloch R. Opposing microRNA families regulate selfrenewal in mouse embryonic stem cells. Nature. 2010;463:621-6.

31. Curtis C, Shah SP, Chin S-F, Turashvili G, Rueda OM, Dunning MJ, et al. The genomic and transcriptomic architecture of 2,000 breast tumours reveals novel subgroups. Nature. 2012;486:346-52

32. Hatzis C, Pusztai L, Valero V, Booser DJ, Esserman L, Lluch A, et al. A genomic predictor of response and survival following taxane-anthracycline chemotherapy for invasive breast cancer. JAMA. 2011;305:1873-81.
33. Lim E, Vaillant F, Wu D, Forrest NC, Pal B, Hart AH, et al. Aberrant luminal progenitors as the candidate target population for basal tumor development in BRCA1 mutation carriers. Nat Med. 2009;15:907-13.

34. Herschkowitz Jl, Zhao W, Zhang M, Usary J, Murrow G, Edwards D, et al. Comparative oncogenomics identifies breast tumors enriched in functional tumor-initiating cells. Proc Natl Acad Sci U S A. 2012;109:2778-83.

35. Green JE, Shibata MA, Yoshidome K, Liu ML, Jorcyk C, Anver MR, et al. The C3(1)/SV40 T-antigen transgenic mouse model of mammary cancer: ductal epithelial cell targeting with multistage progression to carcinoma. Oncogene. 2000;19:1020-7.

36. Ursini-Siegel J, Schade B, Cardiff RD, Muller WJ. Insights from transgenic mouse models of ERBB2-induced breast cancer. Nat Rev Cancer. 2007;7:389-97.

37. Fantozzi A, Christofori G. Mouse models of breast cancer metastasis. Breast Cancer Res. 2006:8:212

38. Neve RM, Chin K, Fridlyand J, Yeh J, Baehner FL, Fevr T, et al. A collection of breast cancer cell lines for the study of functionally distinct cancer subtypes. Cancer Cell. 2006:10:515-27.

39. Liu JC, Deng T, Lehal RS, Kim J, Zacksenhaus E. Identification of tumorsphere- and tumor-initiating cells in HER2/Neu-induced mammary tumors. Cancer Res. 2007;67:8671-81.

40. Guo H, Ingolia NT, Weissman JS, Bartel DP. Mammalian microRNAs predominantly act to decrease target mRNA levels. Nature. 2010;466:835-40.

41. Doench JG, Sharp PA. Specificity of microRNA target selection in translational repression. Genes Dev. 2004;18:504-11.

42. Grimson A, Farh K, Johnston WK, Garrett-Engele P. MicroRNA targeting specificity in mammals: determinants beyond seed pairing. Mol Cell. 2007;27:91-105.

43. Subramanian A, Tamayo P, Mootha VK, Mukherjee S, Ebert BL, Gillette MA, et al Gene set enrichment analysis: a knowledge-based approach for interpreting genome-wide expression profiles. Proc Natl Acad Sci U S A. 2005;102:15545-50.

44. Foley NH, Bray IM, Tivnan A, Bryan K, Murphy DM, Buckley PG, et al. MicroRNA-184 inhibits neuroblastoma cell survival through targeting the serine/threonine kinase AKT2. Mol Cancer. 2010;9:83.

45. Stephens PJ, Tarpey PS, Davies H, Van Loo P, Greenman C, Wedge DC, et al. The landscape of cancer genes and mutational processes in breast cancer. Nature. 2012:486:400-4

46. Vivanco I, Sawyers C. The phosphatidylinositol 3-kinase-AKT pathway in human cancer. Nat Rev Cancer. 2002;2:489-501.

47. Laplante M, Sabatini DM. mTOR signaling in growth control and disease. Cell. 2012;149:274-93.

48. Esteller M. Epigenetic gene silencing in cancer: the DNA hypermethylome. Hum Mol Genet. 2007;16(Spec No 1):R50-9.

49. Toyota M, Suzuki H, Sasaki Y, Maruyama R, Imai K, Shinomura $Y$, et al. Epigenetic silencing of microRNA-34b/c and B-cell translocation gene 4 is associated with CpG island methylation in colorectal cancer. Cancer Res. 2008;68:4123-32

50. Grady WM, Parkin RK, Mitchell PS, Lee JH, Kim Y-H, Tsuchiya KD, et al. Epigenetic silencing of the intronic microRNA hsa-miR-342 and its host gene EVL in colorectal cancer. Oncogene. 2008;27:3880-8.

51. Png KJ, Yoshida M, Zhang XH-F, Shu W, Lee H, Rimner A, et al. MicroRNA-335 inhibits tumor reinitiation and is silenced through genetic and epigenetic mechanisms in human breast cancer. Genes Dev. 2011;25:226-31.

52. Bueno MJ, Pérez de Castro I, Gómez de Cedrón M, Santos J Calin GA, Cigudosa JC, et al. Genetic and epigenetic silencing of microRNA-203 enhances ABL1 and BCR-ABL1 oncogene expression. Cancer Cell. 2008;13:496-506.

53. Dvinge H, Git A, Gräf S, Salmon-Divon M, Curtis C, Sottoriva A, et al. The shaping and functional consequences of the microRNA landscape in breast cancer. Nature. 2013;497:378-82.

54. Liu C, Teng Z-Q, Santistevan NJ, Szulwach KE, Guo W, Jin P, et al. Epigenetic regulation of miR-184 by MBD1 governs neural stem cell proliferation and differentiation. Cell Stem Cell. 2010:6:433-44.

55. Iovino N, Pane A, Gaul U. miR-184 has multiple roles in Drosophila female germline development. Dev Cell. 2009;17:123-33.

56. Shalom-Feuerstein R, Serror L, La Forest Divonne de S, Petit I, Aberdam E, Camargo L, et al. Pluripotent Stem Cell Model Reveals Essential Roles for miR-450b-5p and miR-184 in Embryonic Corneal Lineage Specification. Stem Cells. 2012:30:898-909.

57. Chen Y, Stallings RL. Differential patterns of microRNA expression in neuroblastoma are correlated with prognosis, differentiation, and apoptosis. Cancer Res. 2007:67:976-83. 
58. Malzkorn B, Wolter M, Liesenberg F, Grzendowski M, Stühler K, Meyer HE, et al. Identification and functional characterization of microRNAs involved in the malignant progression of gliomas. Brain Pathol. 2010;20:539-50.

59. Zhou L, Chen J, Li Z, Li X, Hu X, Huang Y, et al. Integrated profiling of microRNAs and mRNAs: microRNAs located on Xq27.3 associate with clear cell renal cell carcinoma. PLoS One. 2010;5, e15224.

60. Porkka KP, Pfeiffer MJ, Waltering KK, Vessella RL, Tammela TL, Visakorpi T. MicroRNA expression profiling in prostate cancer. Cancer Res. 2007;67:6130-5.

61. Tivnan A, Foley NH, Tracey L, Davidoff AM, Stallings RL. MicroRNA-184mediated inhibition of tumour growth in an orthotopic murine model of neuroblastoma. Anticancer Res. 2010;30:4391-5.

62. Yu J, Ryan DG, Getsios S, Oliveira-Fernandes M, Fatima A, Lavker RM. MicroRNA-184 antagonizes microRNA-205 to maintain SHIP2 levels in epithelia. Proc Natl Acad Sci U S A. 2008;105:19300-5.

63. Weitzel RP, Lesniewski ML, Haviernik P, Kadereit S, Leahy P, Greco NJ, et al. microRNA 184 regulates expression of NFAT1 in umbilical cord blood CD4+ T cells. Blood. 2009;113:6648-57.

64. Fenton TR, Gout IT. Functions and regulation of the 70kDa ribosomal S6 kinases. Int J Biochem Cell Biol. 2011;43:47-59.

65. Pende M, Um SH, Mieulet V, Sticker M, Goss VL, Mestan J, et al. S6K1(-/-)/S6K2(-/-) mice exhibit perinatal lethality and rapamycin-sensitive 5'-terminal oligopyrimidine mRNA translation and reveal a mitogen-activated protein kinase-dependent S6 kinase pathway. Mol Cell Biol. 2004;24:3112-24.

66. Sridharan S, Basu A. S6 kinase 2 promotes breast cancer cell survival via Akt. Cancer Res. 2011;71:2590-9.

67. Wang Q, Bailey CG, Ng C, Tiffen J, Thoeng A, Minhas V, et al. Androgen receptor and nutrient signaling pathways coordinate the demand for increased amino acid transport during prostate cancer progression. Cancer Res. 2011:71:7525-36.

68. Kaira K, Oriuchi N, Imai H, Shimizu K, Yanagitani N, Sunaga N, et al. I-type amino acid transporter 1 and CD98 expression in primary and metastatic sites of human neoplasms. Cancer Sci. 2008;99:2380-6.

69. Kobayashi K, Ohnishi A, Promsuk J, Shimizu S, Kanai Y, Shiokawa Y, et al. Enhanced tumor growth elicited by L-type amino acid transporter 1 in human malignant glioma cells. Neurosurgery. 2008;62:493-503. discussion 503-4.

70. Yanagisawa N, Ichinoe M, Mikami T, Nakada N, Hana K, Koizumi W, et al. High expression of L-type amino acid transporter 1 (LAT1) predicts poor prognosis in pancreatic ductal adenocarcinomas. J Clin Pathol. 2012;65:1019-23.

71. Kaira K, Oriuchi N, Imai H, Shimizu K, Yanagitani N, Sunaga N, et al. Prognostic significance of L-type amino acid transporter 1 expression in resectable stage I-III nonsmall cell lung cancer. Br J Cancer. 2008;98:742-8.

72. Sakata T, Ferdous G, Tsuruta T, Satoh T, Baba S, Muto T, et al. L-type amino-acid transporter 1 as a novel biomarker for high-grade malignancy in prostate cancer. Pathol Int. 2009:59:7-18.

73. Kaira K, Sunose Y, Arakawa K, Ogawa T, Sunaga N, Shimizu K, et al. Prognostic significance of L-type amino-acid transporter 1 expression in surgically resected pancreatic cancer. Br J Cancer. 2012;107:632-8.

74. Furuya M, Horiguchi J, Nakajima H, Kanai Y, Oyama T. Correlation of L-type amino acid transporter 1 and CD98 expression with triple negative breast cancer prognosis. Cancer Sci. 2012;103:382-9.

75. Lin EY, Nguyen AV, Russell RG, Pollard JW. Colony-stimulating factor 1 promotes progression of mammary tumors to malignancy. J Exp Med. 2001;193:727-40

76. Wyckoff J, Wang W, Lin EY, Wang Y, Pixley F, Stanley ER, et al. A paracrine loop between tumor cells and macrophages is required for tumor cell migration in mammary tumors. Cancer Res. 2004;64:7022-9.

77. Goswami S, Sahai E, Wyckoff JB, Cammer M, Cox D, Pixley FJ, et al. Macrophages promote the invasion of breast carcinoma cells via a colony-stimulating factor-1/epidermal growth factor paracrine loop. 2005

78. Wang D, Zhang Z, O'Loughlin E, Wang L, Fan X, Lai EC, et al. MicroRNA-205 controls neonatal expansion of skin stem cells by modulating the $\mathrm{Pl}(3) \mathrm{K}$ pathway. Nat Cell Biol. 2013;15:1153-63.
79. Jin Y, Tymen SD, Chen D, Fang ZJ, Zhao Y, Dragas D, et al. MicroRNA-99 Family Targets AKT/mTOR Signaling Pathway in Dermal Wound Healing. PLoS One. 2013;8, e64434.

80. Hu R, Pan W, Fedulov AV, Jester W, Jones MR, Weiss ST, et al. MicroRNA-10a controls airway smooth muscle cell proliferation via direct targeting of the PI3 kinase pathway. FASEB J. 2014;28:2347-57.

81. Wang Y, Liu J, Liu C, Naji A, Stoffers DA. MicroRNA-7 regulates the mTOR pathway and proliferation in adult pancreatic $\beta$-cells. Diabetes. 2013;62:887-95

\section{Submit your next manuscript to BioMed Central and take full advantage of:}

- Convenient online submission

- Thorough peer review

- No space constraints or color figure charges

- Immediate publication on acceptance

- Inclusion in PubMed, CAS, Scopus and Google Scholar

- Research which is freely available for redistribution 